\title{
Melhoria de desempenho acústico de vedação interna de habitação de interesse social usando simulação numérica
}

\author{
Acoustic performance improvement for social interest \\ dwelling internal wall using numerical simulation
}

\begin{abstract}
Isadora Veloso Lima
Gerardo Alves Nogueira Braga Neto

Gabriel Soares Quixaba

Gustavo da Silva Vieira de Melo

Alexandre Luiz Amarante Mesquita

Resumo

${ }^{1}$ Isadora Veloso Lima ${ }^{1}$ Universidade Federal do Pará Belém - PA - Brasil

${ }^{2}$ Gerardo Alves Nogueira Braga

${ }^{3}$ Gabriel Soares Quixaba 3Universidade Federal do Pará Belém - PA - Brasil

${ }^{4}$ Gustavo da Silva Vieira de Melo ${ }^{4}$ Universidade Federal do Pará Belém - PA - Brasil

${ }^{5}$ Alexandre Luiz Amarante Mesquita

${ }^{5}$ Universidade Federal do Pará Belém - PA - Brasil

Recebido em 24/09/20

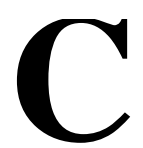

om a publicação da norma de desempenho em edificações habitacionais, NBR 15575:2013, os novos projetos buscam pelo menos o atendimento dos níveis acústicos mínimos de desempenho estabelecidos na norma. Contudo, não é raro encontrar edificações que falham nesses quesitos. No presente trabalho, apresenta-se um estudo de caso de modelagem acústica de uma habitação de interesse social visando a melhor solução para vedação interna vertical da edificação. Medições foram realizadas no interior da edificação e um modelo numérico da edificação foi gerado por meio do método do traçado de raios. O modelo, após calibrado pelo $D_{n T, w}$ (diferença padronizada de nível ponderada) experimental, foi utilizado para realização de simulações numéricas de várias configurações. Finalmente, os resultados das configurações de soluções são discutidos em relação ao seu desempenho acústico.

Palavras-chave: Desempenho acústico. Simulação numérica. Traçados de raios. NBR 15575.

\section{Abstract}

New housing projects aim to meet at least the minimum levels established by the Brazilian standard for residential buildings performance, NBR 15575:2013. However, it is not uncommon to find buildings that fail to meet its criteria. This paper presents a case study consisting of the acoustic modelling of a dwelling in a social housing project, with the aim of finding a better solution for the building's vertical internal walls. Measurements were performed inside the dwelling and a numerical model was generated using the ray tracing method. The model was calibrated by experimental $D_{n T, w}$ (weighted standardized level difference) and used to perform numerical simulations of various configurations. Finally, the results of the solution configurations are discussed with regards to their acoustic performance.
\end{abstract} Aceito em 18/12/20

Keywords: Acoustic performance. Numerical simulation. Ray tracing. NBR 15575. 


\section{Introdução}

Desde 2005, existe uma lei no Brasil que dispõe sobre o Sistema Nacional de Habitação de Interesse Social (SNHIS), com o objetivo de democratizar o acesso à terra urbanizada, habitação digna e sustentável. Um dos resultados desta lei é o Programa Minha Casa Minha Vida (PMCMV), criado em 2009 pelo Governo Federal em parceria com os estados e municípios, gerido pelo Ministério das Cidades e operacionalizado pela Caixa Econômica Federal, tendo sido criado para suprir o novo contexto da necessidade de habitação e qualidade de vida nas áreas urbanas. Após uma década do lançamento do programa foram contratadas 5,5 milhões de unidades habitacionais, com aproximadamente 3,8 milhões de unidades habitacionais entregues (RANGEL et al., 2020).

Em relação à qualidade de vida, um dos principais agentes que afetam uma habitação, trazendo desconfortos e até mesmo enfermidades, é o ruído. Segundo a Organização Mundial da Saúde (OMS) o ruído pode perturbar o trabalho, o descanso, o sono e a comunicação entre seres humanos, podendo provocar reações psicológicas, fisiológicas e ao mesmo tempo patológicas (COSTA; LACERDA; MARQUES, 2013). Portanto, é imperativo que moradias apresentem bom desempenho acústico. Na Europa, desde os anos 80 já havia a preocupação com desempenho de edificações em várias áreas por meio da norma ISO 6241 Performance standards in buildings - Principles for their preparation and factors to be considered (INTERNATIONAL..., 1984). Contudo, no Brasil não havia, por parte do setor de construção civil, o atendimento a essa norma e nem à versão antiga da norma brasileira NBR 10152 (ABNT, 2020a), que estabelece níveis de pressão sonora em ambientes internos de edificações (PROACÚSTICA, 2013). Somente em 2013 foi homologada a norma de desempenho em edificações habitacionais NBR 15575 (ABNT, 2013). Essa norma, com força de lei, é composta por seis partes, as quais apresentam critérios de desempenho para garantir a qualidade de edificações habitacionais. Em relação ao quesito acústica, a norma apresenta os níveis de desempenho em três categorias (mínimo, intermediário e superior) que os sistemas construtivos devem ter para atenuar a transmissão dos ruídos gerados externa e internamente nas edificações habitacionais.

Após a publicação e exigência da NBR 15575 (ABNT, 2013), a Caixa Econômica Federal realizou algumas implementações no Programa "Minha Casa Minha Vida" para atender à norma. Contudo, estudos realizados em edificações do PMCMV ainda mostram o não atendimento à norma de desempenho (BUENO et al., 2019; LORENZI; SILVA FILHO, 2015; PIRES, 2015; KUHN, 2015).

No caso de se buscar uma solução para o baixo desempenho acústico de uma edificação, o uso de simulação numérica de um modelo calibrado da edificação vem ser uma estratégia para se analisarem diferentes configurações virtuais, sem que se façam alterações físicas na edificação, evitando custos desnecessários (NAVARRO; ESCOLANO, 2015; SANTOS FILHO; SPOSTO; CALDAS, 2017). Após comprovada a melhor solução acústica no modelo, executa-se então essa solução fisicamente na edificação.

Nesse contexto, o presente trabalho apresenta um estudo de análise de desempenho de vedação vertical em uma tipologia de habitação do PMCMV, e propõe soluções de fácil implementação, baseado em simulação computacional, para o alcance dos mínimos requisitos da NBR 15575 (ABNT, 2013). Inicialmente, foram realizadas medições de transmissão acústica na edificação para verificação do atendimento à norma de desempenho. Após a constatação do não atendimento, foram realizadas simulações acústicas da edificação por meio do método de traçado de raios (BRANDÃO, 2016), a fim de analisar as modificações no modelo e prever o desempenho acústico causado pelas modificações virtuais. Várias soluções de modificações foram simuladas e calculados os respectivos resultados de desempenho acústico, visando à solução ótima de desempenho mínimo, de acordo com a NBR 15575 (ABNT, 2013).

\section{Fundamentação teórica}

\section{Isolação de ruído aéreo entre ambientes}

A energia sonora proveniente de uma fonte acústica, ao atingir uma parede divisória entre dois recintos, é parcialmente refletida, parcialmente absorvida (transformada em calor), e parcialmente transmitida. A parcela de energia sonora que será transmitida dependerá das características construtivas da divisória. Em geral, quanto mais rígida e densa for, menor transmissão acústica ocorrerá, e essa partição é dita acusticamente isolante. Outro fator que influencia no isolamento é o fato de não se usar apenas uma partição, mas uma sequência de obstáculos para o som ter mais dificuldade de se propagar. $\mathrm{O}$ uso de paredes duplas, janelas com vidros duplos, ou a combinação de materiais de diferentes densidades é importante para o bom isolamento acústico.

158 Lima, I. V.; Braga Neto, G. A. N.; Quixaba, G. S.; Melo, G. da S. V. de; Mesquita, A. L. A. 
Uma forma simples de quantificar a isolação acústica de uma determinada parede entre dois ambientes é por meio da diferença de níveis de pressão sonora $(D)$ entre o ambiente onde se situa a fonte sonora (emissor) e o ambiente receptor do ruído (Equação 1):

$D=L_{1}-L_{2}[d B]$

Eq. 1

Sendo:

$L_{1}$ o nível de pressão sonora médio em dB no ambiente emissor do ruído; e

$L_{2}$ o nível de pressão sonora médio em $\mathrm{dB}$ no ambiente receptor.

Contudo, para se mensurar a isolação de uma parede divisória, deve-se levar em conta não só a diferença de nível $(D)$, como também a área da parede e a absorção da sala receptora, pois o ruído em salas receptoras reverberantes é maior que em salas absorvedoras. Para ensaios laboratoriais em câmara reverberantes, usa-se o índice $(R)$, índice de redução sonora aérea da parede, também conhecido como perda de transmissão $(P T)$, dada por (Equação 2):

$R=L_{1}-L_{2}+10 \log \left(\frac{S}{A}\right)[d B]$

Eq. 2

Sendo que $S$ é a área da parede $\mathrm{em}^{2}, A$ é a área de absorção sonora equivalente da sala receptora $\mathrm{em}^{2}$, dada por $A=0,161\left(V / T_{R}\right)$, em que $V$ é o volume da sala receptora em $\mathrm{m}^{3}$, e $T_{R}$ é o tempo de reverberação da sala receptora dado em $\mathrm{s}$.

No caso de medições de isolação sonora em campo, utiliza-se a diferença padronizada de nível entre ambientes $D_{n T}$ (Equação 3):

$D_{n T}=L_{1}-L_{2}+10 \log \left(\frac{T_{R}}{T_{0}}\right)[d B]$

Eq. 3

Sendo que $T_{0}$ é o tempo reverberação de referência $\left(T_{0}=0,5 \mathrm{~s}\right)$.

Os valores de $D_{n T}$ exprimem a quantidade de isolamento sonoro de determinada partição isolante por banda de frequência. No entanto, é usualmente utilizado um valor único de isolamento, a diferença padronizada de nível ponderada, $D_{n T, w}$, que é calculada de acordo com a norma ISO 717-1 (INTERNATIONAL..., 2013). O procedimento de cálculo é ilustrado no exemplo apresentado na Figura 1, e em linhas gerais, a curva de $D_{n T}$ em função da frequência (linha vermelha), obtida em campo, deve ser ajustada a uma curva de referência especificada na norma (linha preta), de forma que a curva de referência seja movida (linha tracejada) em passos de $\pm 1 \mathrm{~dB}$ por banda de frequência, de forma que a soma dos desvios desfavoráveis (valores positivos da subtração dos valores medidos de $D_{n T}$ menos a curva de referência deslocada para cada banda de frequência), tais como definidos na norma, seja o maior possível, porém, não ultrapassando $32 \mathrm{~dB}$. O ajuste que mais se aproximar de $32 \mathrm{~dB}$ é utilizado para a obtenção do número único, $D_{n T, w}$, o qual é o novo valor de referência na frequência de $500 \mathrm{~Hz}$.

Figura 1 - llustração de determinação do $D_{n T, w}$ a partir do $D_{n T}$ usando a curva de referência da norma ISO 717-1 (INTERNATIONAL..., 2013)

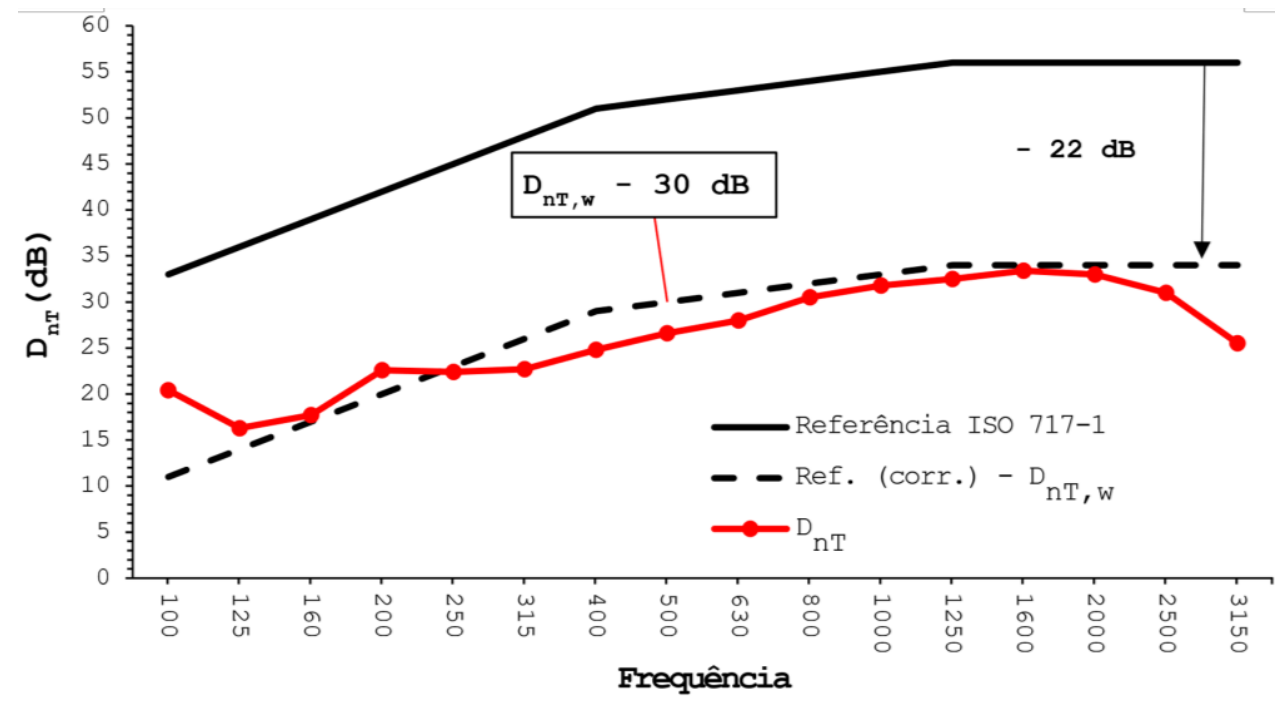


$\mathrm{Na}$ Figura 1, a curva de referência foi deslocada $22 \mathrm{~dB}$ para baixo, a soma dos valores desfavoráveis encontrados foi de $31,8 \mathrm{~dB}$ e por fim o valor de $D_{n T, w}$ correspondente à frequência de $500 \mathrm{~Hz}$ foi de $30 \mathrm{~dB}$.

Também se pode chegar ao número único utilizando a norma ISO 717-1 (INTERNATIONAL..., 2013), a partir dos valores de perda de transmissão obtidas em laboratório, em câmara reverberante padrão. Nesse caso, o número único é definido como índice de redução sonora ponderado, $R_{w}$.

\section{NBR 15575 - Desempenho acústico de vedações internas verticais}

A norma de desempenho NBR 15575 (ABNT, 2013) entrou em vigor em 19 de fevereiro de 2013, tornandose válida a partir de 19 de julho do mesmo ano (SORGATO et al., 2014). Essa norma é composta por seis partes, as quais apresentam critérios de desempenho para garantir a qualidade de edificações habitacionais. No quesito acústica, a norma é dividida em análise de desempenho de instalações, equipamentos prediais e sistemas hidrossanitários, sistema de pisos, sistema de vedações verticais internas (paredes), sistema de vedações verticais externas (fachadas) e, finalmente, sistema de coberturas.

Em relação ao isolamento ao ruído aéreo de sistemas de vedação verticais internas (paredes), a norma apresenta os níveis mínimos de desempenho (mínimo, intermediário e superior) por meio da avaliação do parâmetro diferença padronizada de nível ponderada, $D_{n T, w}$, um número único. Para se chegar ao $D_{n T, w}$, inicialmente determina-se o $D_{n T}$, o que pode ser realizado por meio de dois métodos, com procedimentos diferentes: engenharia e simplificado de campo. O método de engenharia é obtido seguindo-se a norma NBR ISO 16283-1 (ABNT, 2018), e o método de simplificado de campo segue a norma NBR ISO 10052 (ABNT, 2020b). O método de engenharia é mais preciso que o método simplificado. Em seguida, por meio dos procedimentos da norma ISO 717-1 (INTERNATIONAL..., 2013), usando uma curva de referência, chegase ao número único $D_{n T, w}$, como descrito na seção anterior. Para a NBR 15575 (ABNT, 2013), os valores de referência para paredes verticais são dados pela Tabela 1 . Na Tabela 2 são apresentados os valores de $D_{n T, w}$ correlacionados com a inteligibilidade da fala entre os ambientes emissor e receptor.

Tabela 1 - Isolamento ao ruído aéreo de sistemas de vedação verticais internas (paredes)

\begin{tabular}{|c|c|c|c|c|c|}
\hline \multirow{2}{*}{\multicolumn{2}{|c|}{ Parâmetro }} & \multirow{2}{*}{ Elemento } & \multicolumn{3}{|c|}{ Desempenho } \\
\hline & & & MIN & INT & SUP \\
\hline \multirow{6}{*}{$\begin{array}{l}\text { Diferença } \\
\text { padronizada de } \\
\text { nível ponderada }\end{array}$} & \multirow{6}{*}{$D_{n T, w}$} & $\begin{array}{l}\text { Paredes entre unidades habitacionais } \\
\text { autônomas (paredes de geminação) nas } \\
\text { situações onde não haja ambiente } \\
\text { dormitório }\end{array}$ & $\geq 40 \mathrm{~dB}$ & $\geq 45 \mathrm{~dB}$ & $\geq 50 \mathrm{~dB}$ \\
\hline & & $\begin{array}{l}\text { Paredes entre unidades habitacionais } \\
\text { autônomas (paredes de geminação) no } \\
\text { caso de pelo menos um dos ambientes } \\
\text { ser dormitório }\end{array}$ & $\geq 45 \mathrm{~dB}$ & $\geq 50 \mathrm{~dB}$ & $\geq 55 \mathrm{~dB}$ \\
\hline & & $\begin{array}{l}\text { Parede cega de dormitório entre uma } \\
\text { unidade habitacional e áreas comuns de } \\
\text { trânsito eventual, tais como corredores e } \\
\text { escadaria nos pavimentos }\end{array}$ & $\geq 40 \mathrm{~dB}$ & $\geq 45 \mathrm{~dB}$ & $\geq 50 \mathrm{~dB}$ \\
\hline & & $\begin{array}{l}\text { Parede cega de salas e cozinhas entre } \\
\text { uma unidade habitacional e áreas comuns } \\
\text { de trânsito eventual, tais como } \\
\text { corredores e escadarias nos pavimentos }\end{array}$ & $\geq 30 \mathrm{~dB}$ & $\geq 35 \mathrm{~dB}$ & $\geq 40 \mathrm{~dB}$ \\
\hline & & $\begin{array}{l}\text { Parede cega entre unidade habitacional e } \\
\text { áreas comuns de permanência de } \\
\text { pessoas, atividades de lazer e atividades } \\
\text { esportivas, tais como home theather, } \\
\text { salas de ginástica, salão de festas, salão } \\
\text { de jogos, banheiros e vestiários coletivos, } \\
\text { cozinhas e lavanderias coletivas }\end{array}$ & $\geq 45 \mathrm{~dB}$ & $\geq 50 \mathrm{~dB}$ & $\geq 55 \mathrm{~dB}$ \\
\hline & & $\begin{array}{l}\text { Conjunto de paredes e portas de unidades } \\
\text { distintas separadas por um hall }\end{array}$ & $\geq 40 \mathrm{~dB}$ & $\geq 45 \mathrm{~dB}$ & $\geq 50 \mathrm{~dB}$ \\
\hline
\end{tabular}

Fonte: NBR 15575 (ABNT, 2013).

Nota: valores em negrito são obrigatórios e os demais informativos.

160 Lima, I. V.; Braga Neto, G. A. N.; Quixaba, G. S.; Melo, G. da S. V. de; Mesquita, A. L. A. 
Tabela 2 - Influência da DnT,w sobre a inteligibilidade da fala, para ruído no ambiente interno em torno de 35 a $40 \mathrm{~dB}$

\begin{tabular}{l|c}
\hline Inteligibilidade de fala alta no recinto adjacente & Isolamento sonora, $\boldsymbol{D}_{\boldsymbol{n} T, \boldsymbol{w}}[\mathbf{d B}]$ \\
\hline Claramente audível: ouve e entende & 35 \\
Audível: ouve, entende com dificuldade & 40 \\
Audível: não entende & 45 \\
Não audível & $\geq 50$ \\
\hline
\end{tabular}

Fonte: NBR 15575 (ABNT, 2013).

\section{Modelagem numérica de salas}

A caracterização acústica de uma sala ou ambiente envolve o conhecimento das funções de resposta ao impulso (IRFs) do sistema sala-fonte-receptor, a qual é composta pelo som direto e pelas reflexões que o som sofre no ambiente. A determinação das IRFs pode ser realizada por meio de métodos numéricos ou experimentais. Dentre os métodos numéricos há os métodos baseados na resolução da equação da onda (como, por exemplo, métodos dos elementos finitos, método dos elementos de contorno e método das diferenças finitas) e os métodos baseados na propagação geométrica da energia sonora. Dentre os métodos dessa segunda classe há o método de traçado de raios e o método de fontes virtuais, que simulam os três fenômenos mais importantes da propagação do som em salas: absorção, reflexão especular e reflexão difusa (TENENBAUM; CAMILO, 2004). No presente trabalho, foi usado o método de traçado de raios por meio do software Odeon $^{\mathcal{O}} 12.2$ Combined (CHRISTENSEN, 2013).

\section{Método \\ Descrição da edificação}

A edificação em estudo foi construída pelo Programa Nacional de Habitação Rural, sendo enquadrada no Programa Minha Casa, Minha Vida da Caixa Econômica Federal. Trata-se de uma construção com fundação com alicerce (pedra preta com aguada) e baldrame (concreto armado), supraestrutura formada por dez pilares (concreto armado), percinta (concreto armado), estrutura do telhado em madeira de lei com imunização e telhas cerâmicas tipo plan. A paredes de vedação internas e externas são construídas com blocos cerâmicos de 6 furos de $11,5 \times 14 \times 24 \mathrm{~cm}$ e as paredes receberam o acabamento em argamassa, chapisco e reboco, e a pintura foi realizada em tinta PVA, totalizando uma espessura de cerca de $16 \mathrm{~cm}$. Internamente, a casa possui área interna útil de $36 \mathrm{~m}^{2}$ com dois quartos, sala, cozinha e banheiro. Na Figura 2 é apresentada a frente da edificação.

Quanto aos acabamentos internos da residência, no piso foi utilizada uma cerâmica PEI IV - tipo A e no teto foi utilizado forro de PVC. Entretanto, as paredes da cozinha e banheiro receberam cerâmica até uma altura de 1,50 m e, acima dessa parte, utilizou-se a mesma pintura padrão do interior da habitação. A esquadria de portas é de madeira mista com $43 \mathrm{~mm}$ de espessura e a esquadria das janelas em alumínio com vidros simples com $3 \mathrm{~mm}$ de espessura.

\section{Medições in situ}

$\mathrm{Na}$ edificação foram realizadas medições de nível de pressão sonora e de tempo de reverberação, a fim de se determinar a diferença padronizada de nível ponderada $\left(D_{n T, w}\right)$ da partição de vedação vertical interna que separa um dos dormitórios (ver na Figura 3). Os ensaios de isolamento acústico seguiram as recomendações da norma NBR ISO 16283-1 (ABNT, 2018). Portanto, foi utilizado o método de engenharia, mais preciso.

Os ambientes medidos foram sala/cozinha e o quarto simples, sendo que no momento dos ensaios acústicos in situ a residência ainda não havia sido entregue ao proprietário, portanto há ausência de mobiliário. Seguindo as recomendações da norma NBR ISO 16283-1 (ABNT, 2018), as posições de fonte sonora e microfone foram selecionadas nos ambientes. De acordo com o distanciamento em relação às superfícies dos ambientes e entre os arranjos de fonte/microfone, como já mencionado. A norma também sugere que as alturas de fonte sonora e microfone em relação ao chão sejam 1,5 e 1,2 m, respectivamente. 
Figura 2 - Frente da edificação

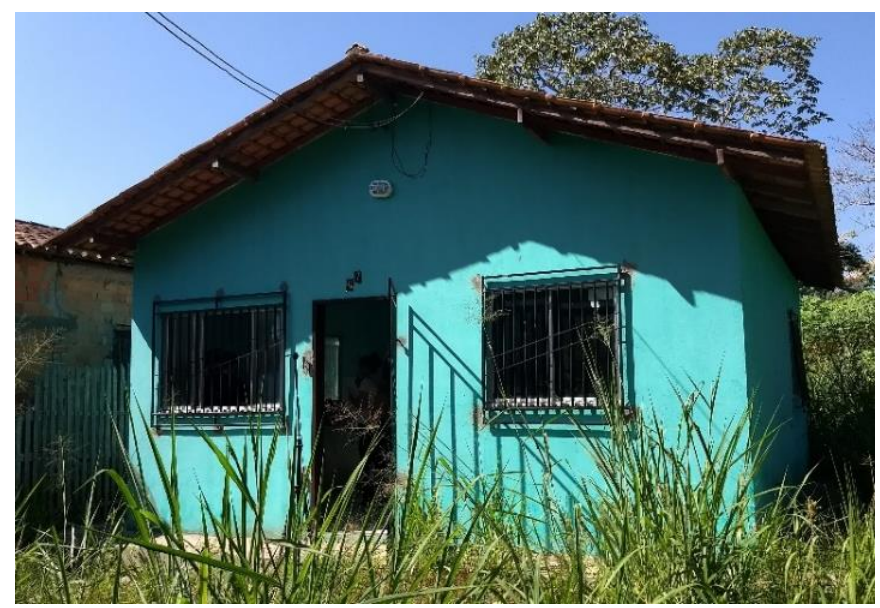

Figura 3 - Planta baixa da edificação e destaque para a partição acusticamente avaliada

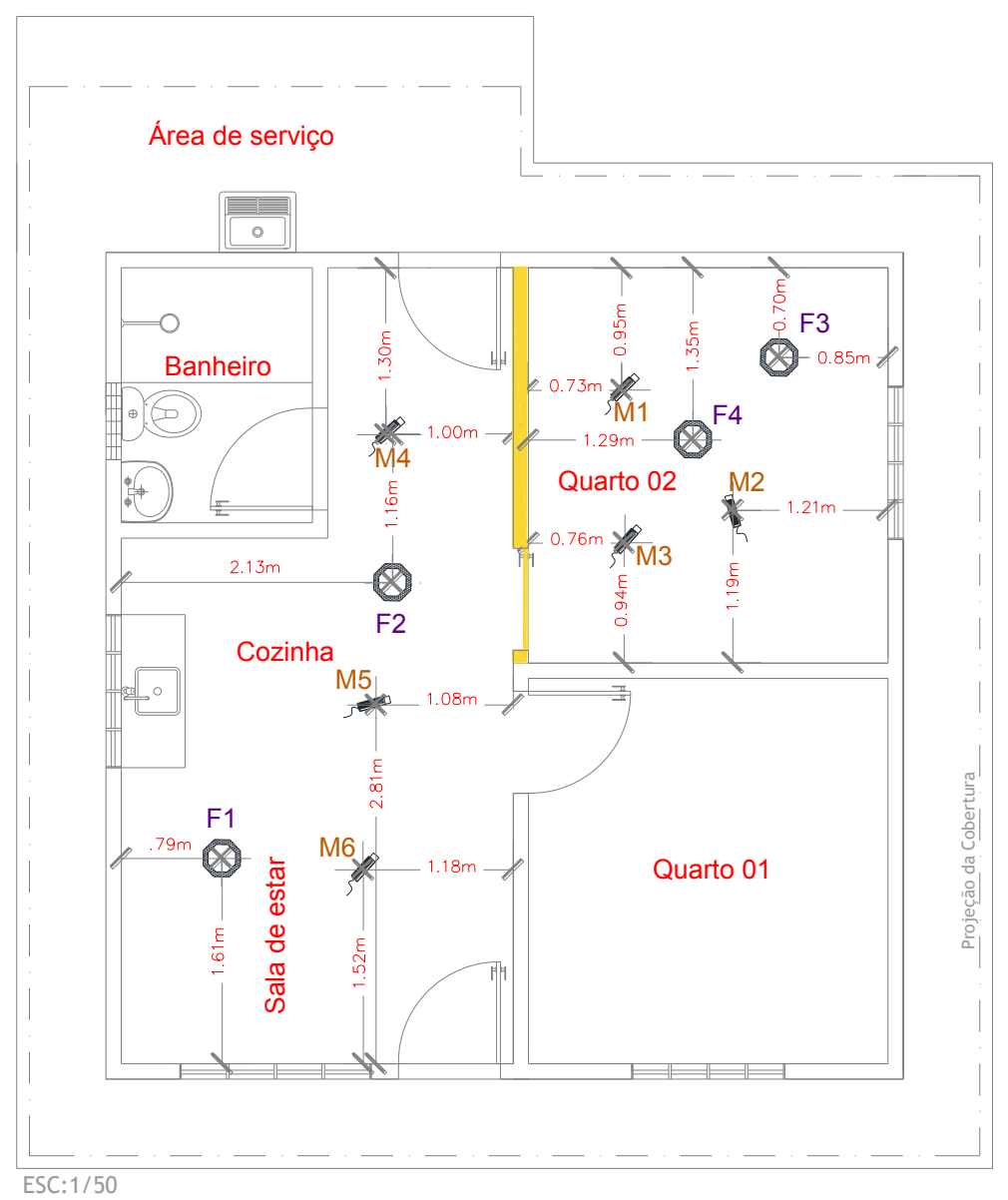

Os sinais foram captados e gerados, utilizando-se o analisador B\&K Investigator 2260. O ruído rosa gerado foi enviado para o amplificador B\&K 2716 e, na sequência, emitido pela fonte sonora B\&K 4296. O sistema de medição foi devidamente calibrado, in situ, no momento da medição com o calibrador B\&K 4231 e os transdutores utilizados foram microfones de campo difuso B\&K 4189. $L_{1}$ e $L_{2}$ foram medidos em bandas de terço de oitava entre 100 e $3.150 \mathrm{~Hz}$, nas medições foram obtidas três médias temporais de três posições do microfone para o cálculo do nível médio espacial. Além da necessidade de ser determinar o tempo de reverberação experimental para o ajuste do modelo numérico, o parâmetro também é utilizado para o cálculo

162 Lima, I. V.; Braga Neto, G. A. N.; Quixaba, G. S.; Melo, G. da S. V. de; Mesquita, A. L. A. 
do $D_{n T, w}$. Portanto, é fundamental obter os valores de $T_{R}$ do ambiente receptor para avaliar a transmissão sonora. $\mathrm{O} T_{R}$ foi obtido através de medições realizadas também de acordo com a norma NBR ISO 3382-2 (ABNT, 2017) (ver nas Figuras 4 e 5). As medições foram efetivadas pela combinação de duas posições de fontes e três pontos receptores, sendo realizadas três medições em cada ponto receptor. Após medidos os níveis $L_{1}$ e $L_{2}$, além de $T_{R}$, foi determinado o $D_{n T}$ e, em seguida, por meio da norma ISO 717-1 (INTERNATIONAL..., 2013), determinou-se o $D_{n T, w}$ para ser confrontado com a norma de desempenho NBR 15575 (ABNT, 2013).

\section{Ensaios em laboratório}

Visando obter as perdas de transmissão dos elementos construtivos da residência para se fazer a modelagem acústica da residência, determinou-se a perda de transmissão sonora do forro de PVC instalado na edificação. Ensaios de laboratório foram realizados fazendo uso de um par de câmaras reverberantes em escala reduzida (emissora e receptora), projetadas e validadas por Toutonge (2006) e utilizadas por Guimarães (2011). Seus resultados, apesar de não serem de uma câmara em escala real, fornecem valores aproximados de perda de transmissão, suficientes para serem incorporados ao modelo numérico. Na Figura 6 pode-se visualizar uma amostra do forro de PVC de 0,6 $\mathrm{m} \times 0,6 \mathrm{~m}$ sendo posicionada entre as duas câmaras acústicas. $\mathrm{O}$ sistema de medição foi o mesmo utilizado no ensaio de campo.

\section{Figura 4 - Medições de níveis sonoros e tempo de reverberação na cozinha e sala de estar}

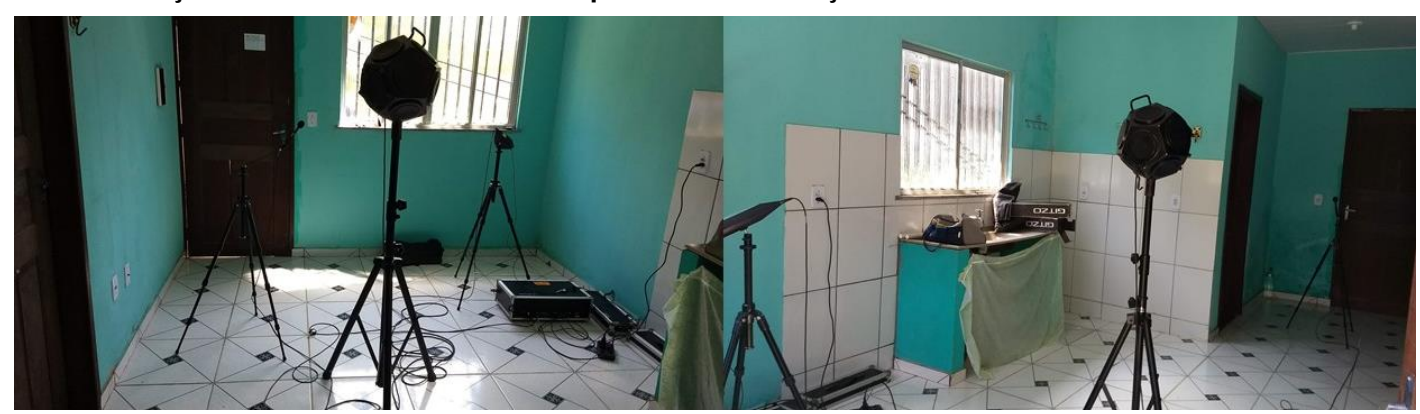

Figura 5 - Medições de níveis de sonoros e tempo de reverberação no quarto 02

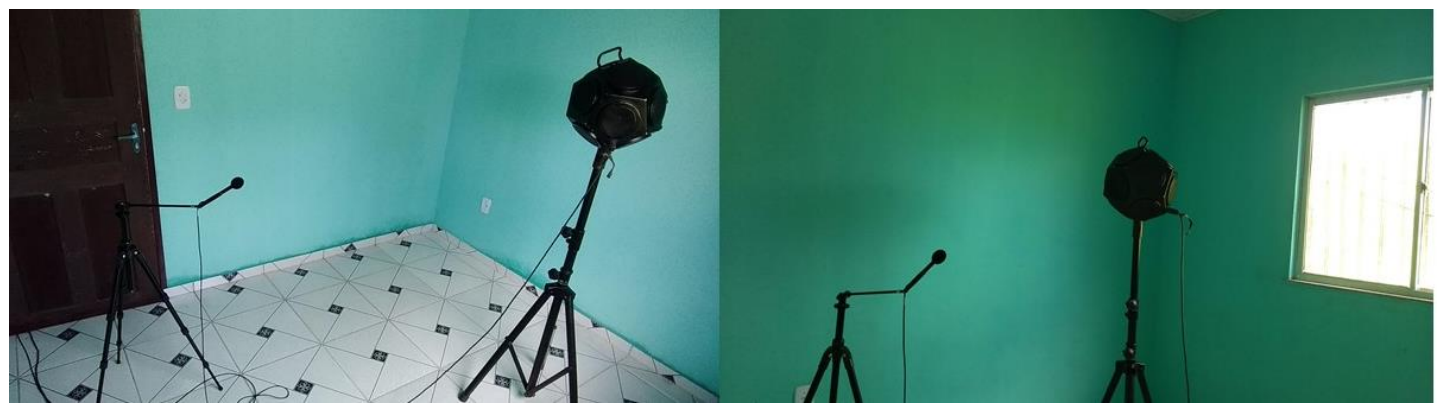

Figura 6 - Ensaio do forro de PVC

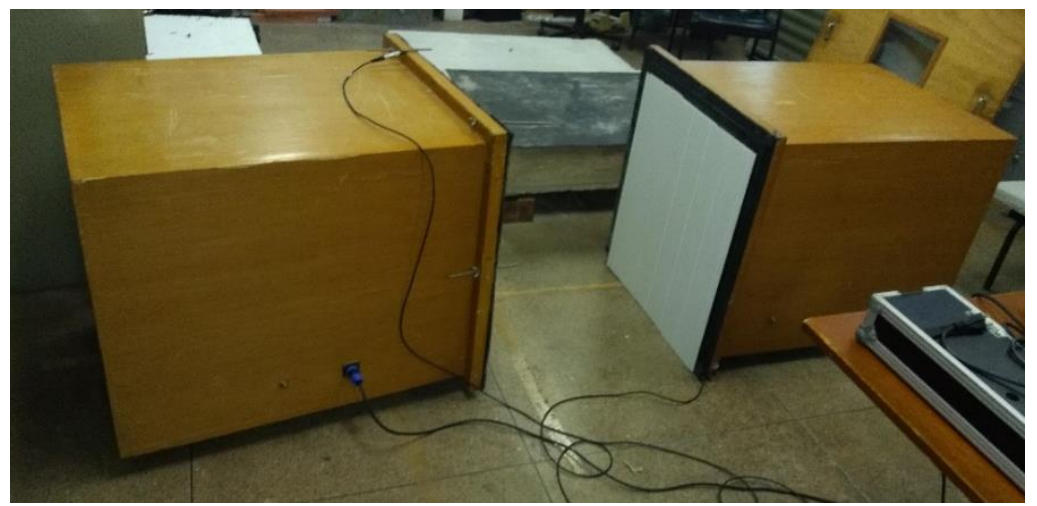


Os ensaios foram necessários por não terem sido encontrados na literatura valores de perda de transmissão condizentes com este material existente na unidade habitacional. Para os demais elementos (portas, paredes, etc.), as perdas de transmissão foram encontradas na literatura.

\section{Simulação computacional}

Para estudar o comportamento acústico de uma sala a partir da predição acústica com um programa computacional são necessárias informações de suas características geométricas, das propriedades de absorção e espalhamento sonoro das superfícies, assim como das características de potência sonora e de diretividade da fonte que geraria o som (LIMA; VERGARA, 2018).

Nesse estudo foi utilizado o software de acústica de raios Odeon ${ }^{\mathcal{O}} 12.2$ Combined. O software é amplamente utilizado na simulação acústica de ambientes fechados, e possui a funcionalidade de aplicar às paredes divisórias dos recintos um determinado isolamento sonoro, considerando uma transmissão direta da energia sonora entre ambientes. Para o cálculo de transmissão sonora no ODEON, apenas $10 \%$ dos raios passam através da partição de interesse, enquanto os $90 \%$ restantes são mantidos dentro da sala de origem, para a simulação dos parâmetros acústicos de salas. Em geral, recomenda-se usar um número maior de raios (o dobro do que necessário para acústica de salas) ao fazer cálculos de transmissão para garantir que uma quantidade suficiente de raios chegue ao ambiente receptor (CHRISTENSEN, 2013).

Inicialmente, a partir dos desenhos da planta da edificação foi possível a criação do modelo 3D no software Trimble SketchUp 2019. O modelo 3D da habitação é uma representação simplificada das superfícies, de acordo com verificação arquitetônica, desconsiderando pequenas espessuras, reentrâncias e detalhes desnecessários para a acústica estatística/geométrica, a Figura 7 ilustra as superfícies e as partições consideras no modelo conforme as propriedades acústicas das Tabela 3 e 4 . No modelo, assim como nos ensaios experimentais, não são considerados os mobiliários e objetos normalmente encontrados em habitações (sofás, cortinas, cadeiras, etc.). Para cada superfície existente no modelo é atribuída uma camada para representar os materiais e elementos do ambiente. Após a construção da geometria, o modelo foi importado para o software Odeon.

No Odeon, foram inseridas propriedades acústicas: absorção sonora para todas as superfícies do recinto e índice de redução sonora, $R$, para as partições. As fontes e receptores foram inseridos através da ferramenta Source Receiver List. Os receptores necessitaram apenas das especificações de posição, pois são modelados no software como receptores pontuais. Já no caso das fontes, se fez necessária a especificação do tipo de fonte (pontual, em linha ou de superfícies múltiplas), sua posição, potência sonora e diretividade. As fontes foram modeladas como pontuais e omnidirecionais, pois melhor representam os procedimentos de medição realizados e recomendados pela NBR ISO 3382-2 (ABNT, 2017). O valor do ganho sonoro considerado na fonte modelada correspondeu à potência fornecida pela fonte real utilizada no momento das medições, sendo de $80 \mathrm{~dB}$.

Figura 7 - Modelo geométrico e computacional da edificação com as indicações dos elementos utilizados na análise

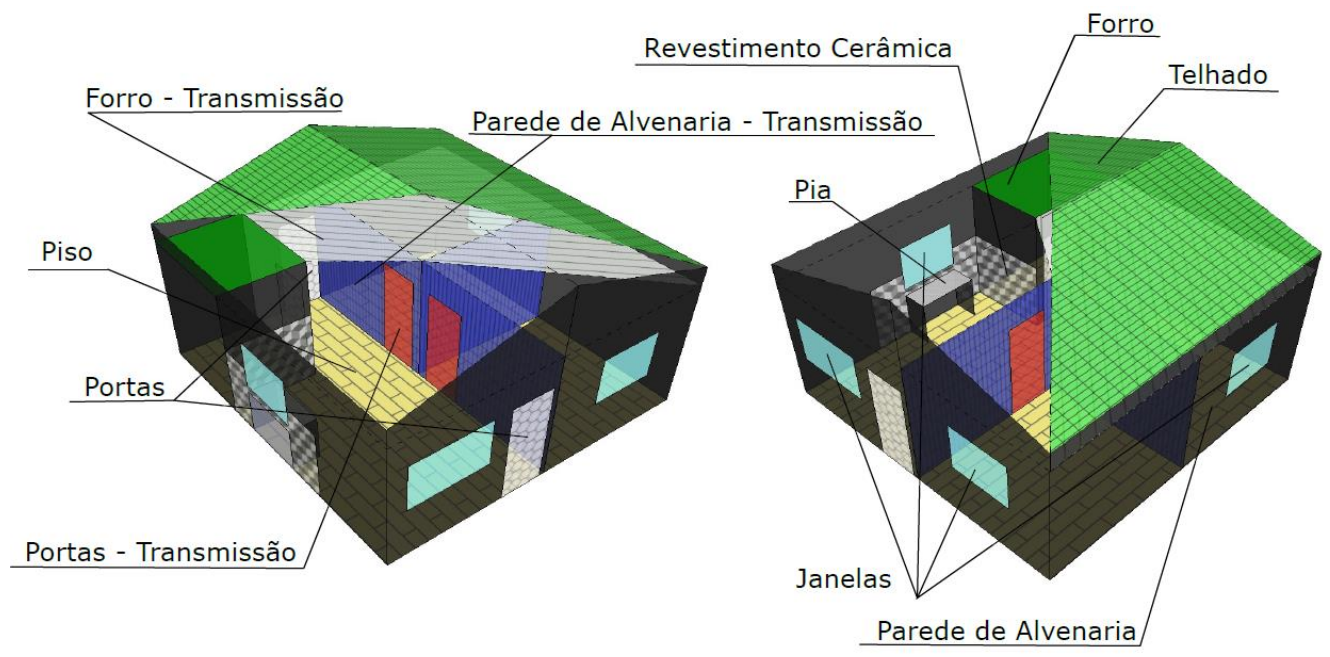

164 Lima, I. V.; Braga Neto, G. A. N.; Quixaba, G. S.; Melo, G. da S. V. de; Mesquita, A. L. A. 
Tabela 3 - Valores de coeficiente de absorção sonora adotados para as superfícies internas da casa

\begin{tabular}{c|c|c|c|c|c|c}
\hline \multirow{2}{*}{ Material } & \multirow{2}{*}{ Área $\left(\mathbf{m}^{\mathbf{2}}\right)$} & \multicolumn{5}{|c}{ Coeficiente de absorção sonora $(\boldsymbol{\alpha})$} \\
\cline { 3 - 6 } & & $\mathbf{1 2 5}$ & $\mathbf{2 5 0}$ & $\mathbf{5 0 0}$ & $\mathbf{1 0 0 0}$ & $\mathbf{2 0 0 0}$ \\
\hline Portas* & 8,40 & 0,24 & 0,19 & 0,14 & 0,09 & 0,13 \\
Parede de alvenaria** & 83,45 & 0,01 & 0,05 & 0,06 & 0,07 & 0,09 \\
Telhado** & 39,46 & 0,03 & 0,03 & 0,03 & 0,04 & 0,05 \\
Forro*** & 37,49 & 0,01 & 0,01 & 0,01 & 0,02 & 0,02 \\
Revestimento cerâmico* & 4,63 & 0,01 & 0,01 & 0,01 & 0,02 & 0,02 \\
Piso* & 37,49 & 0,01 & 0,01 & 0,01 & 0,02 & 0,02 \\
Janelas** & 6,30 & 0,35 & 0,25 & 0,18 & 0,12 & 0,07 \\
Pia** & 0,6 & 0,3 & 0,25 & 0,2 & 0,1 & 0,1 \\
\hline
\end{tabular}

Fonte: *Lima e Vergara (2018), ${ }^{* *}$ Christensen (2013) e ${ }^{* * *}$ Ansay e Zanin (2016).

Tabela 4 - Valores de isolamento para os elementos de vedação de interesse em bandas de oitava

\begin{tabular}{|c|c|c|c|c|c|c|c|c|}
\hline \multirow{2}{*}{ Material } & \multirow{2}{*}{$\begin{array}{c}\text { Espessura } \\
\quad(\mathbf{m m})\end{array}$} & \multirow{2}{*}{$\begin{array}{c}\text { Densidade } \\
\text { superficial } \\
(\mathrm{kg} / \mathrm{m} 2)\end{array}$} & \multicolumn{5}{|c|}{ Índice de redução sonora - R (dB) } & \multirow{2}{*}{$\begin{array}{c}\text { Indice de } \\
\text { redução } \\
\text { sonora } \\
\text { ponderado- } \\
\mathbf{R}_{w}(\mathbf{d B}) \\
-\end{array}$} \\
\hline & & & 125 & 250 & $\mathbf{5 0 0}$ & 1000 & 2000 & \\
\hline Portas* & 43 & 25 & 12,0 & 13,0 & 14,0 & 16,0 & 18,0 & 17 \\
\hline $\begin{array}{c}\text { Parede de } \\
\text { Alvenaria** }\end{array}$ & 160 & 305 & 36,5 & 36,3 & 37,4 & 39,8 & 46,2 & 42 \\
\hline Forro & 7 & 4 & 34,5 & 25,9 & 13,7 & 20,8 & 25,4 & 19 \\
\hline
\end{tabular}

Fonte: *Caproni (2012) e **Santos Neto (2006).

A Figura 8 ilustra de maneira esquemática os processos que envolveram a etapa de simulação computacional no Odeon e metodologia geral da pesquisa. Após as etapas descritas anteriormente, iniciou-se o processo de calibração do modelo. Nessa etapa, as propriedades acústicas foram ajustadas dentro de suas faixas permissíveis, até que o tempo de reverberação $T_{R}$ do ambiente e o $D_{n T}$ da parede analisada obtivessem acurácia satisfatória.

Na Tabela 3 são apresentados os valores de coeficiente de absorção sonora para as superfícies internas da casa e na Tabela 4 os valores de isolamento adotados para os elementos de vedação da partição de interesse no modelo computacional.

Os coeficientes adotados, tanto de absorção sonora, quanto de isolamento sonoro, foram escolhidos de acordo com a similaridade apresentada nas descrições (material constituinte, espessura, superfície de acabamento, etc.) da biblioteca do software e de acordo com a literatura, a exemplo de Lima e Vergara (2018), Ansay e Zanin (2016), Caproni (2012) e Santos Neto (2006). Vale destacar que o procedimento de escolhas dos materiais foi interativo, pois fontes literárias diferentes podem apresentar valores diferentes para os coeficientes de um mesmo tipo de material, de modo que foram escolhidos os que levaram o modelo a melhor se ajustar aos resultados reais obtidos in situ. Como ressaltado anteriormente, para o forro de PVC, não foram encontrados dados de isolamento na literatura, e, portanto, foram necessárias medições laboratoriais para determinar a sua perda de transmissão sonora.

\section{Resultados e discussões}

\section{Resultados experimentais}

No intuito de verificar o desempenho em relação ao isolamento acústico da parede que separa um quarto do ambiente conjugado sala/cozinha, foram realizadas medições de nível de pressão sonora e tempo de reverberação, conforme descrito na seção Medições in situ. Com os valores médios dessas grandezas obtidos, obteve-se o gráfico de $D_{n T}$ em função da frequência (curva vermelha na Figura 1), e em seguida o número único $D_{n T, w}$ por meio do procedimento descrito na norma ISO 717-1 (INTERNATIONAL..., 2013), conforme ilustra a Figura 9. 
Figura 8 - Fluxograma das etapas de trabalho de simulação no software Odeon

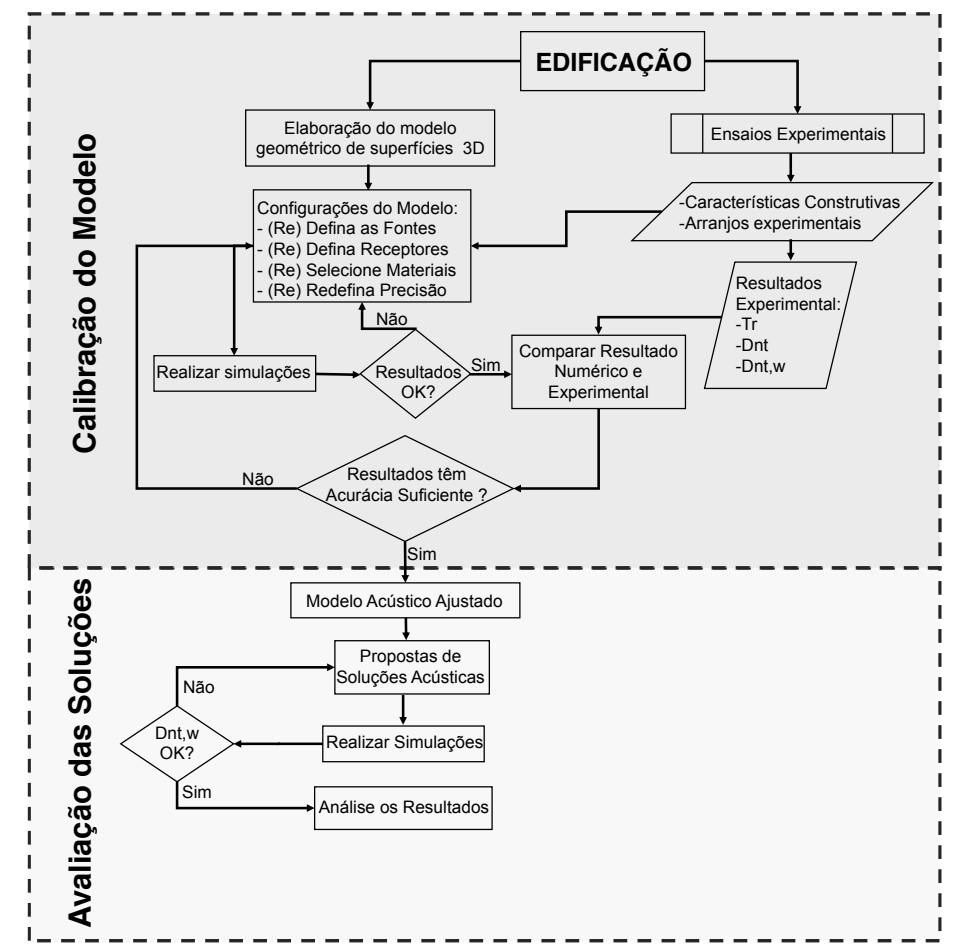

Figura 9 - Determinação do DnT,w da parede que separa quarto da sala/cozinha

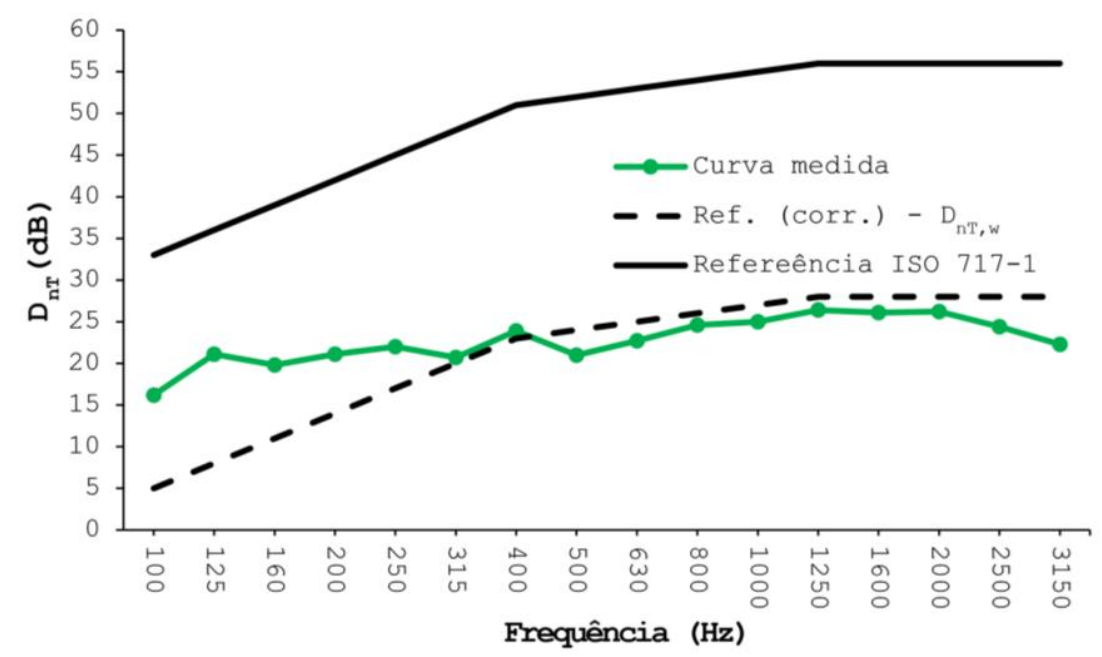

De acordo com a curva deslocada mostrada na Figura 9, para a frequência de $500 \mathrm{~Hz}$, o valor de $D_{n T, w}$ é igual a $23 \mathrm{~dB}$, o qual está aquém dos níveis mínimos requeridos pela norma NBR 15575 (ABNT, 2013). Nota-se que tal déficit no isolamento se deve a dois elementos acusticamente vulneráveis, a porta e o forro de PVC.

Como o resultado do desempenho acústico ficou abaixo dos valores mínimos exigidos pela norma, foram testadas, via modelagem numérica, novas soluções acústicas nessa parede. Para a modelagem da casa são necessários os valores de coeficiente de absorção e de perda de transmissão dos elementos que compõem o modelo da casa. Esses parâmetros estão disponíveis na literatura, com exceção da perda de transmissão $(R)$ do forro de PVC. Dessa forma, foram feitas medições desse parâmetro conforme descrito na seção Ensaios em laboratório. Os valores encontrados no experimento são apresentados na Figura 10 em bandas de oitava, e o valor de $R_{w}$ encontrado conforme a ISO 717-1 (INTERNATIONAL..., 2013) foi de $19 \mathrm{~dB}$, um valor de perda de transmissão considerado baixo. 


\section{Resultados de simulação numérica}

\section{Propriedades dos materiais e ajuste de sensibilidade do modelo}

As configurações de cálculo utilizadas (ver Tabela 5) foram sendo ajustadas ao longo do processo de validação do modelo, de acordo com os resultados encontrados. Tomou-se como ponto de partida a recomendação do software de que o comprimento da resposta impulsiva utilizada deve cobrir pelo menos 2/3 do tempo de reverberação calculado. Assim, foi necessário conferir previamente as estimativas do tempo de reverberação, $T_{R}$, por meio da ferramenta quick estimated reverberation times realizados no Odeon com as equações analíticas para então definir o comprimento da resposta ao impulso. Como as estimativas dos maiores tempos de reverberação da sala foram próximas de $1,70 \mathrm{~s}$, o comprimento da resposta impulsiva foi definido em $3.000 \mathrm{~ms}$.

Os números de raios tardios, raios iniciais e a ordem de transição foram definidos por meio da convergência dos resultados, da inspeção da curva de decaimento para a resposta de um único receptor e do desvio com relação aos dados medidos, feitos a cada aumento gradativo do número de raios e da ordem. Os resultados começaram a convergir para os valores de 1.000 raios tardios. Já a ordem de transição de valor 1 e o número de 10.000 raios iniciais aproximaram os valores simulados aos medidos para os 1.000 raios tardios adotados. Além disso, a curva de decaimento obtida, exposta na Figura 11, não apresentou picos ou quedas bruscas, indicando que a quantidade de raios tardios já é suficiente para a acurácia do modelo.

Para a concepção do modelo foi preciso ainda identificar o caminho de transmissão sonora entre os ambientes emissor e receptor que fosse condizente com a realidade e que melhor se aproximasse dos resultados experimentais. Assim, optou-se por considerar uma transmissão sonora via paredes, porta e forro entre ambientes, como ilustrado na Figura 12, a qual apresenta a trajetória para 3 raios com ordens de reflexões máximas de 100. Os raios são lançados a partir da fonte P1(ver Figura 12(a)). O primeiro raio emitido (raio em vermelho na Figura 12(b)), no ambiente da cozinha, é transmitido pela porta de acesso ao quarto sendo refletido nesse ambiente e por fim transpassa o forro; o segundo raio transita principalmente pelo forro (raio em vermelho na Figura 12(c)); e o terceiro raio (raio em vermelho na Figura 12(d)) sofre reflexões pelo ambiente da cozinha e sala e é transmitido para os quartos pelas paredes e forro.

Figura 10 - Valores do R experimental do forro de PVC

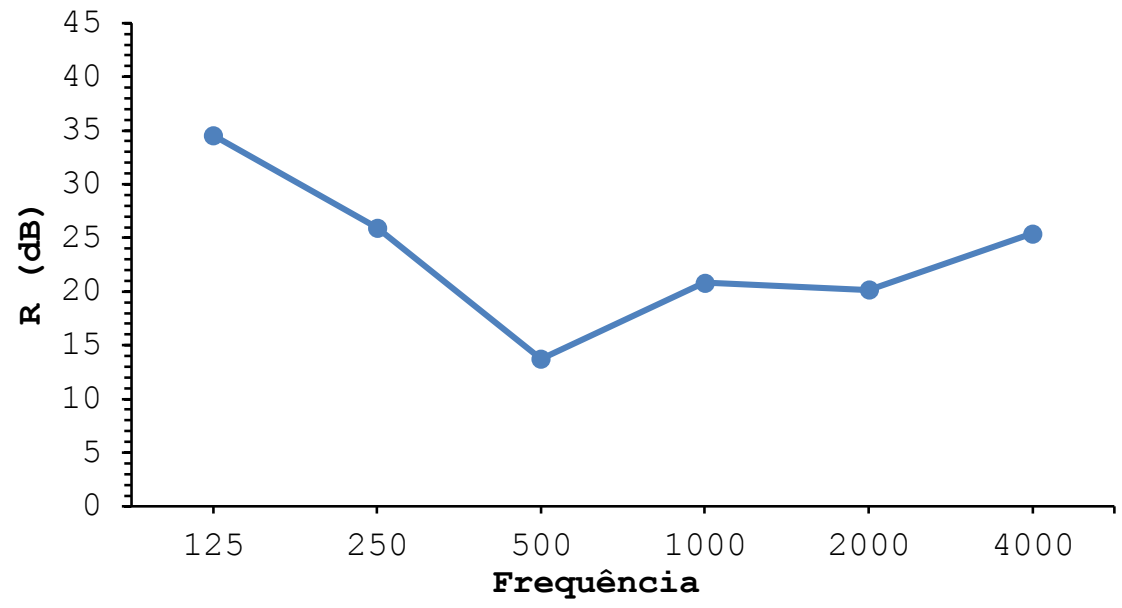

Tabela 5 - Parâmetros de cálculo da simulação

\begin{tabular}{c|c}
\hline Parâmetros de cálculo & Valor \\
\hline Comprimento da resposta impulsiva & $3,0 \mathrm{~s}$ \\
Número de raios tardios & 1.000 \\
Número de raios iniciais & 10.000 \\
Ordem de transição & 1 \\
\hline
\end{tabular}


Figura 11 - Curvas de decaimento com os ajustes de cálculo já selecionados

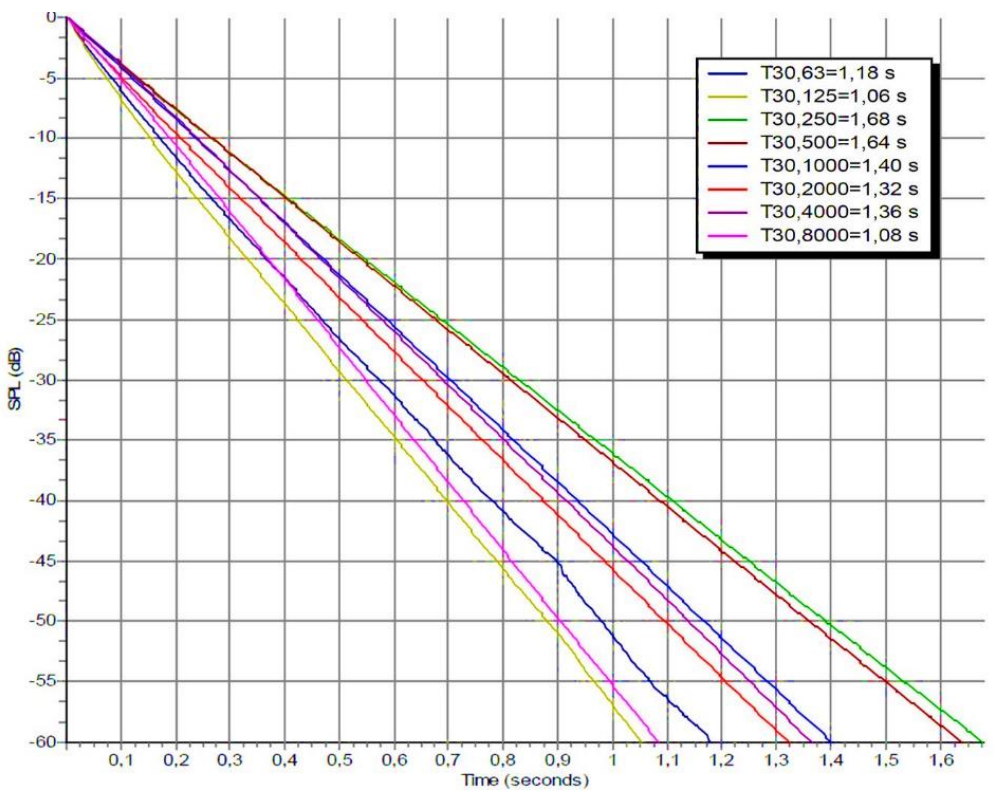

Figura 12 - Transmissão sonora entre as partições da edificação

a)

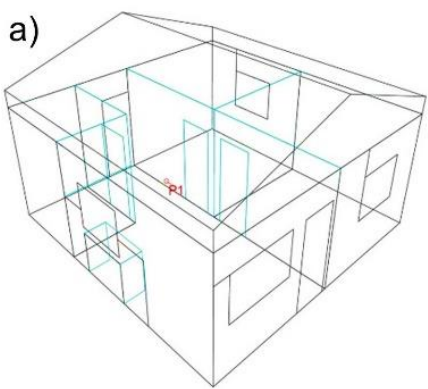

C)

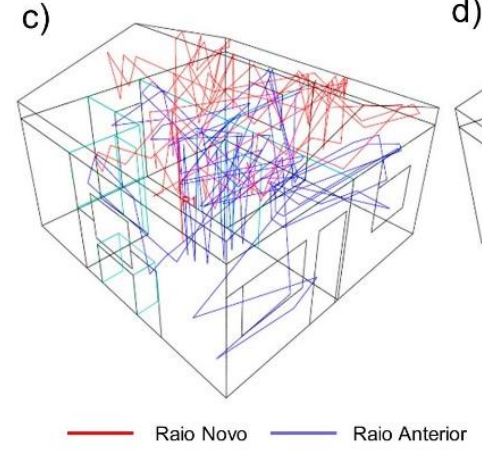

b)

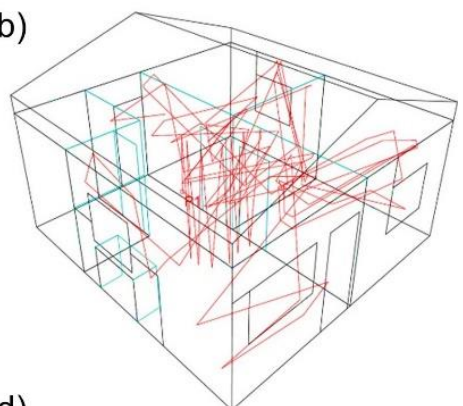

d)

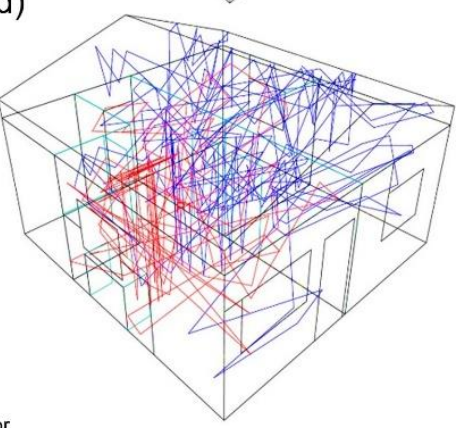

Pelo fato de o software considerar apenas uma transmissão direta sonora de um recinto para outro adjacente, não foi considerada transmissão sonora por flancos, assim como a influência de defeitos na execução das partições isolantes (frestas) que possam reduzir o seu isolamento, o que pode resultar na modelagem um valor de isolamento superior ao valor real. Rindel e Christensen (2008) sugerem que para contornar tais obstáculos os valores de $R$ adotados já apresentem os valores mais próximos à realidade in situ.

De acordo com os resultados de $D_{n T}$ para a vedação analisada, expressos na Figura 13, chega-se à conclusão de que o caminho de transmissão proposto é válido e as considerações realizadas convergiram para uma boa aproximação entre valores experimentais e numéricos de $D_{n T}$, de forma que o desvio máximo obtido foi de apenas $2,2 \mathrm{~dB}$ e o desvio médio foi de $1,4 \mathrm{~dB}$.

168 Lima, I. V.; Braga Neto, G. A. N.; Quixaba, G. S.; Melo, G. da S. V. de; Mesquita, A. L. A. 
Figura 13 - Comparação entre os valores de DnT numérico e experimental

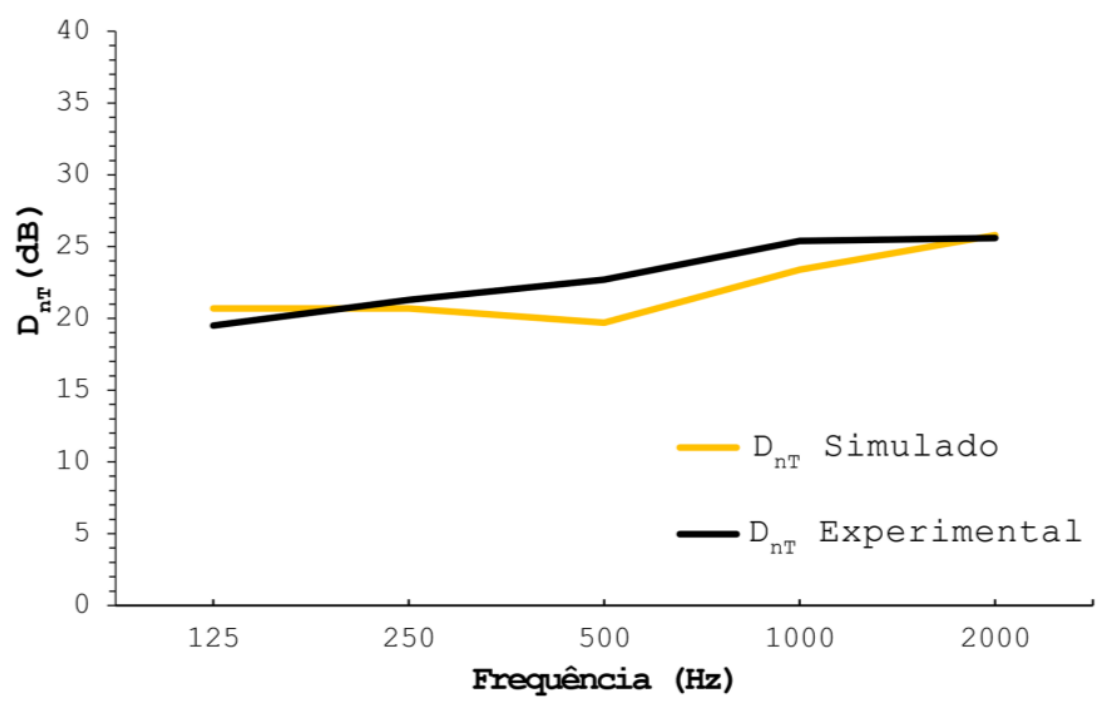

\section{Validação do modelo}

Buscou-se então calibrar o modelo a partir dos resultados experimentais de tempo de reverberação $\left(T_{R}\right), D_{n T}$ e $D_{n T, w}$. Desses 3 parâmetros, apenas o $T_{R}$ é calculado diretamente pelo software Odeon. No entanto, o programa oferece os valores de nível de pressão sonora por ponto de medição, e assim $D_{n T}$ e $D_{n T, w}$ foram calculados a partir da Equação 3 e pelo procedimento da ISO 717-1 (INTERNATIONAL..., 2013), explicitado na Figura 1.

O critério que mensura a diferença aceitável entre o modelo computacional e o modelo real recebe o nome de diferença apenas perceptível (just noticeable difference, JND) (LIMA; VERGARA, 2018).

Os resultados das simulações, quando comparados aos das medições, devem estar dentro das faixas de JND obtidas dos resultados in situ. Os valores de JND utilizados para os parâmetros são extraídos da norma NBR ISO 3382-2 (ABNT, 2017) O recomendado é que a diferença entre valores medidos e simulados deva ser de até uma unidade de JND do parâmetro acústico analisado, para então assegurar um processo de simulação realista, pois esta seria a menor variação do parâmetro percebida por um ouvinte em condições normais (SANTOS, 2019). Todavia, desvios de até 2 JND podem ser considerados toleráveis (VORLÄNDER, 1995).

Para o tempo de reverberação, a norma estipula um JND de $5 \%$; já para os parâmetros $D_{n T}$ e $D_{n T, w}$ não há um JND determinado; no entanto, para parâmetros acústicos baseados no nível de pressão sonora, como o fator de força do som $(\mathrm{G})$ e a clareza $\left(\mathrm{C}_{80}\right)$, o JND é de $1 \mathrm{~dB}$. Ferreira e Zannin (2007), ao realizarem validações de modelos computacionais, nas medições in situ do parâmetro acústico $R$, consideraram um JND de $3 \mathrm{~dB}$ como aceitável.

A Figura 14 apresenta a comparação entre os valores de tempo de reverberação simulados e medidos. Notase que adotando uma diferença aceitável de $10 \%$, ou 2 JND, de acordo com a norma NBR ISO 3382-2 (ABNT, 2017), as bandas de frequência de 125, 500 e $1.000 \mathrm{~Hz}$ ficaram fora dos limites estipulados, apresentando desvios em 14\%, 30\% e 13\%, respectivamente, ou na ordem de até 6 JND. No entanto, os valores simulados foram considerados próximos o suficiente dos medidos para o cálculo do $D_{n T}$, como mostra a Figura 15, na qual é apresentada a comparação entre os valores de $D_{n T}$ calculados com os tempos de reverberação experimentais e simulados. Observou-se uma diferença máxima de apenas $1,1 \mathrm{~dB}$ e média de $0,5 \mathrm{~dB}$. Logo, pode-se afirmar que por mais que o $T_{R}$ não esteja dentro dos limites de JND em sua totalidade, os valores simulados possuem precisão o suficiente para o cálculo do $D_{n T}$ e $D_{n T, w}$.

A validação dos valores de $D_{n T}$ obtidos via simulação computacional são apresentados na Figura 16. Foram estipulados valores aceitáveis de diferença entre o experimental e o simulado de até $3 \mathrm{~dB}$ (3 JND). Nota-se que para todas as bandas de frequência, a excessão da banda de $500 \mathrm{~Hz}$, as diferenças entre os valores experimentais e simulados ficaram abaixo de $2 \mathrm{~dB}$. Já para a banda de frequência em questão, foi observada uma diferença superior no limite de $3 \mathrm{~dB}$, o que não influnciou na acurácia do parâmetro $D_{n T w}$, o qual obteve valor de $23 \mathrm{~dB}$ (ver nas Figuras 16 e 17). 
Figura 14 - Comparação entre os valores de TR simulados e experimentais

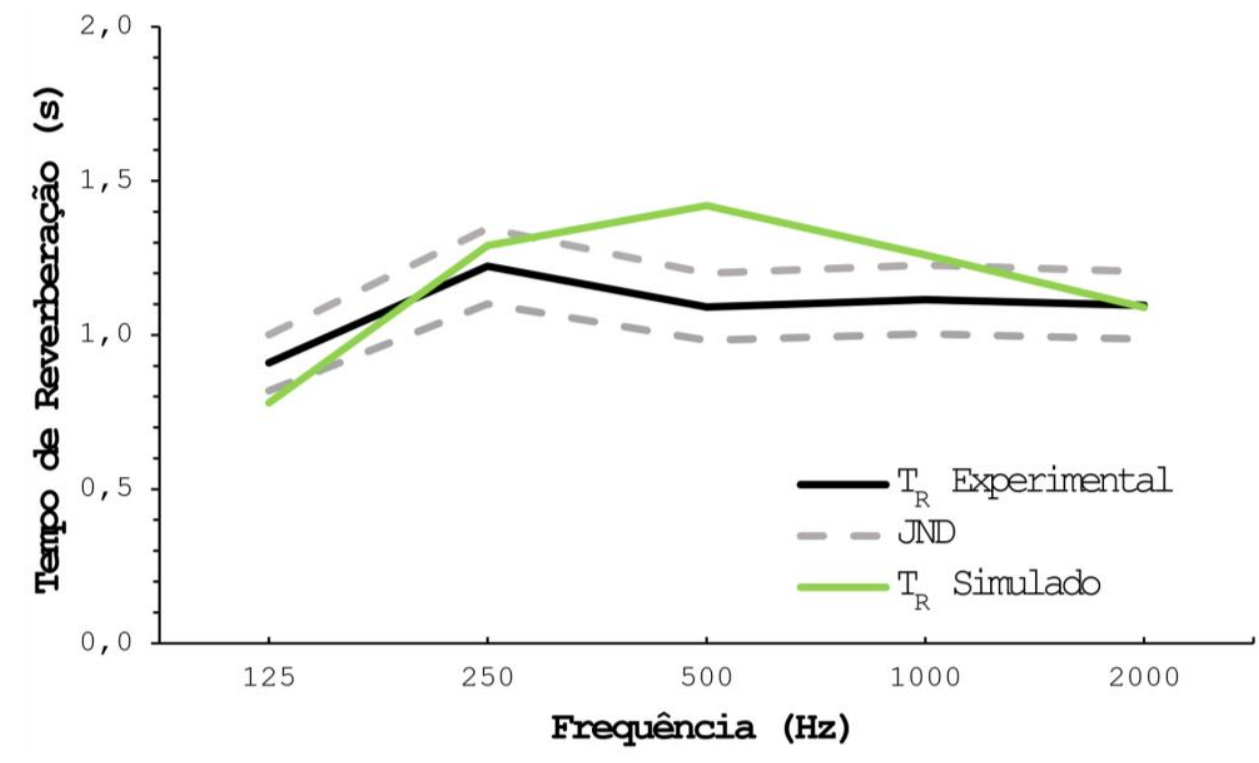

Figura 15 - Comparação entre os valores de DnT calculados com o TR experimental e com o TR simulado

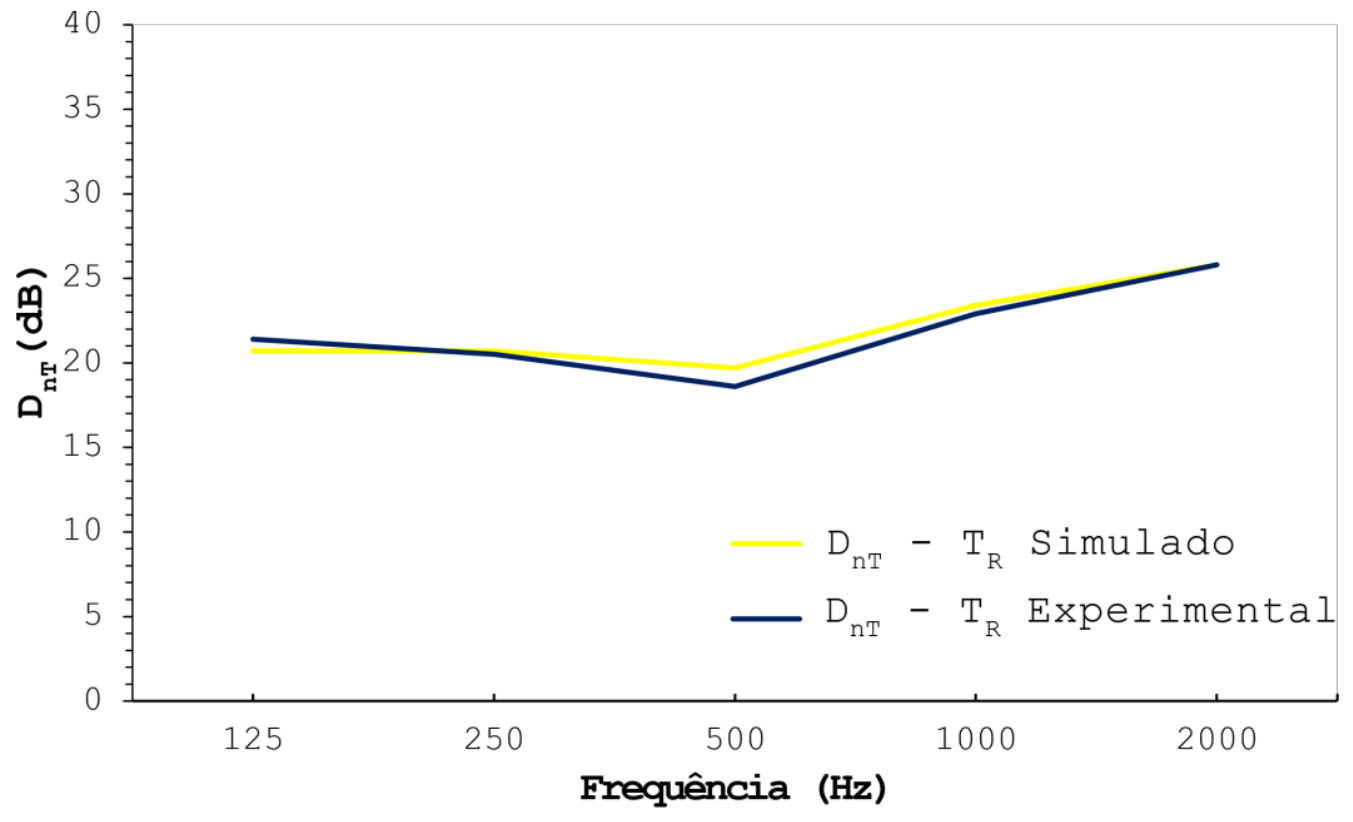


Figura 16 - Comparação entre os valores de DnT simulados e experimentais

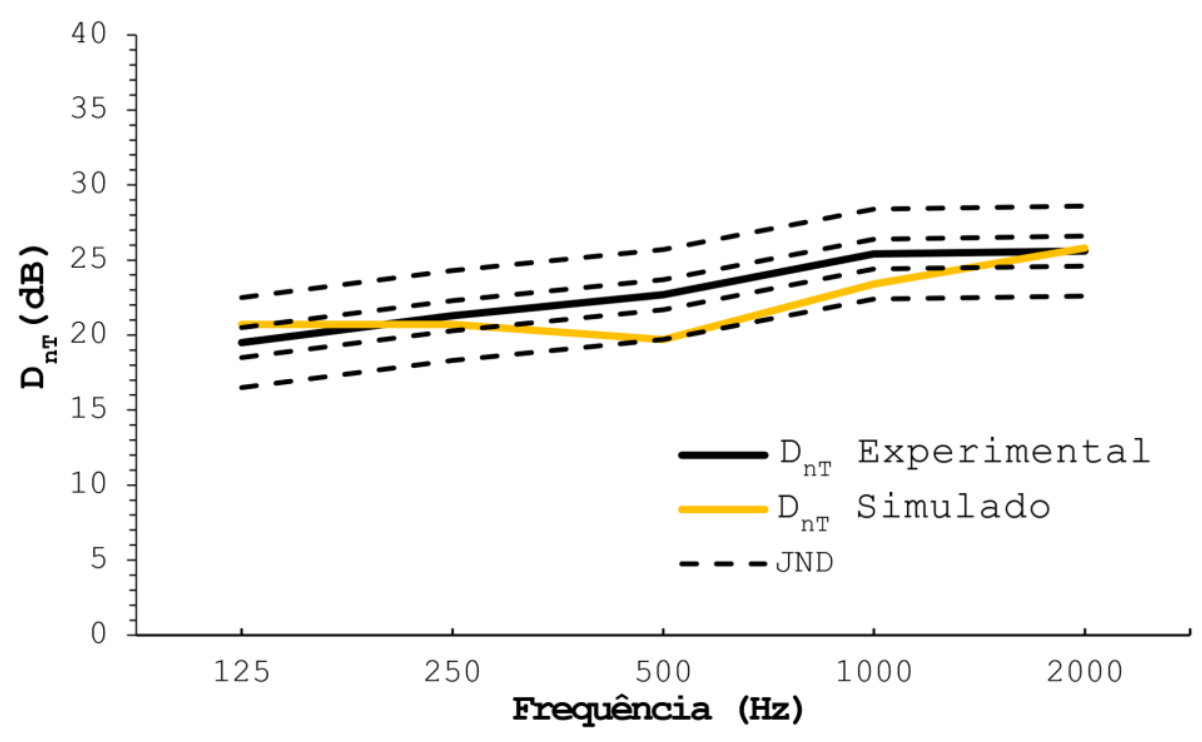

Figura 17 - Valores de DnT por banda de oitava e valor de DnT,w para o modelo computacional validado

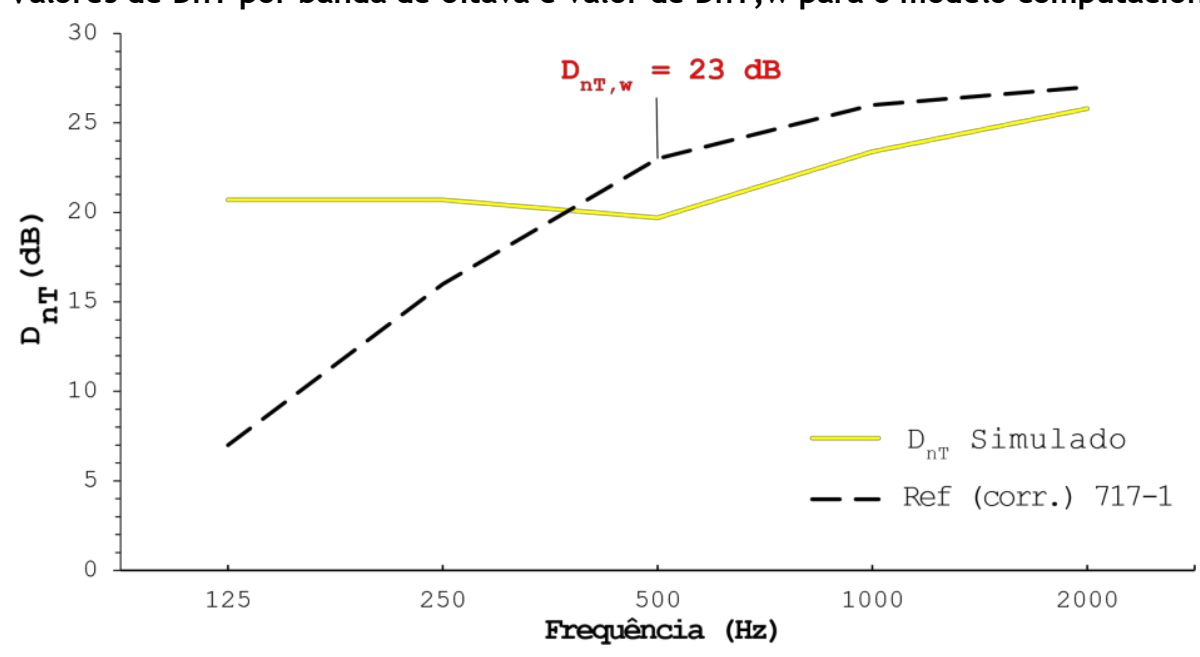

\section{Proposta de alterações para atendimento à Norma NBR 15575}

Sendo observado que o valor de isolamento sonoro entre os ambientes estudados não atende aos critérios mínimos exigidos pela NBR 15575 (ABNT, 2013), buscou-se com o modelo numérico ajustado e validado fazer proposições de possíveis soluções de forma a atender o valor mínimo da $D_{n T, w}$ de $45 \mathrm{~dB}$ (ver Tabela 1). As soluções foram propostas (Tabela 6) levando em consideração, além do aumento do desempenho acústico do sistema de vedação vertical, o custo agregado a essa melhoria, tendo em vista que o objeto é uma habitação do PMCMV e, portanto, há um limite de orçamento que não permite soluções elaboradas e onerosas, como portas acústicas, paredes e forros duplos, sistemas de box-in-box, etc.

Primeiramente as propostas de melhorias se basearam na substituição dos elementos construtivos por outros com $R_{w}$ maior, todavia as substituições impactam fortemente no custo. Assim, analisando o estudo de transmissão sonora apresentado na Figura 12, e correlacionando-o com os valores de isolamento sonoro da Tabela 4, nota-se a possibilidade de se utilizar a parede de alvenaria (elemento com maior $R_{w}$ ) com uma partição para a cavidade formada entre o forro de PVC e o telhado, dificultando a propagação pelo entreforro.

O elemento de maior fragilidade no sistema de isolamento do estudo é a porta, sendo que as portas existentes na residência estudada possuem folha montada com madeira mista oca normalmente instalada nos batentes (de forma a apresentar frestas em seu perímetro). Utilizando um método interativo com os diversos tipos de 
portas existentes na literatura, observou-se como melhor opção a que está descrita em Caproni (2012), conforme apresentado na Tabela 4. Portanto, os resultados são analisados com a substituição das portas existentes por portas de madeira bem encaixadas no batente (Porta 2), com $R_{w}$ de $27 \mathrm{~dB}$, conforme calculado por Caproni (2012) (ver na Tabela 7).

A primeira solução proposta (Solução 1) foi prolongar verticalmente as paredes de alvenaria que dividem os compartimentos até ficarem o mais próximo possível do telhado (como ilustrado na Figura 18), pois de acordo com Halliwell e Quirt (1991), a transmissão sonora entre duas salas adjacentes através do espaço entre o forro e o teto (condição essa similar à encontrada no objeto de estudo) pode ser resolvida de duas maneiras: aumentando o isolamento sonoro do forro, ou bloqueando a transmissão pelo espaço acima do forro entre os dois ambientes. Como resultado, obteve-se um aumento de $2 \mathrm{~dB}$ no valor de $D_{n T, w}$ (ver na Figura 22), aumento este ainda insuficiente para o atendimento dos critérios mínimos exigidos pela norma NBR 15575 (ABNT, 2013).

A segunda solução buscada (Solução 2) também objetivou reduzir a transmissão sonora via forro; porém, nesse caso substituiu-se o forro de PVC por outro em gesso (ver Figura 18), fixado em esquadria de madeira, conforme descrito por Bistafa (2011) (ver na Tabela 7). Com isso, de acordo com a Figura 22 obteve-se um acréscimo de $1 \mathrm{~dB}$ no valor de $D_{n T, w}$.

A terceira solução proposta (Solução 3) foi trocar as portas existentes, pelo modelo de Porta 2, conforme a Tabela 7 (ver Figura 19), tendo em vista que, segundo Caproni (2012), frestas em portas, tal como observado no presente estudo de caso, depreciam a isolação acústica de forma significativa. Assim, obteve-se $D_{n T, w}$ igual a $29 \mathrm{~dB}$ (ver na Figura 22), o que representa um aumento significativo, tendo em vista que se trata de uma porta não acústica (sendo apenas de madeira e bem fixada aos batentes), porém ainda inferior ao critério mínimo normativo.

Tabela 6 - Resultados das soluções acústicas propostas para a habitação

\begin{tabular}{c|l|c}
\hline Solução & \multicolumn{1}{|c}{ Descrição } & D $_{\mathbf{n T}, \mathbf{w}}$ \\
\hline 1 & $\begin{array}{l}\text { Prolongar verticalmente as paredes internas de forma a ficarem rentes ao } \\
\text { telhado }\end{array}$ & 25 \\
\hline 2 & Trocar o forro de PVC por forro de gesso simples & 24 \\
\hline 3 & $\begin{array}{l}\text { Trocar as portas existentes por portas de madeira bem encaixadas nos } \\
\text { batentes com } \mathrm{R}_{\mathrm{w}} \text { de } 27 \mathrm{~dB}\end{array}$ & 29 \\
\hline 4 & $\begin{array}{l}\text { Prolongar verticalmente as paredes internas de forma a ficarem rentes ao } \\
\text { telhado e portas de madeira bem encaixadas nos batentes }\end{array}$ & 35 \\
\hline 5 & $\begin{array}{l}\text { Prolongar todas as paredes do entreforro e utilizar porta maciças de } \\
\text { madeira com espessura de } 66 \text { mm e } \mathrm{R}_{\mathrm{w}} \text { de } 34 \text { dB }\end{array}$ & 40 \\
\hline 6 & $\begin{array}{l}\text { Prolongar todas as paredes do entreforro e utilizar porta maciças de } \\
\text { madeira com espessura de } 66 \text { mm e R } \mathrm{R}_{\mathrm{w}} \text { de 34 dB e trocar o forro de PVC } \\
\text { por forro de gesso simples }\end{array}$ & 40 \\
\hline 7 & $\begin{array}{l}\text { Alterar a planta baixa da habitação, prolongar todas as paredes do } \\
\text { entreforro e utilizar porta maç̧as de madeira com espessura de } 66 \mathrm{~mm} \text { e } \\
\mathrm{R}_{\mathrm{w}} \text { de } 34 \text { dB }\end{array}$ & 46 \\
\hline
\end{tabular}

Tabela 7 - Valores de isolamento dos elementos propostos nas soluções

\begin{tabular}{|c|c|c|c|c|c|c|c|c|}
\hline \multirow[t]{2}{*}{ Material } & \multirow{2}{*}{$\begin{array}{c}\text { Espessura } \\
\quad(\mathbf{m m})\end{array}$} & \multirow{2}{*}{$\begin{array}{c}\text { Densidade } \\
\text { superficial } \\
(\mathrm{kg} / \mathrm{m} 2)\end{array}$} & \multicolumn{5}{|c|}{$\begin{array}{c}\text { Índice de redução sonora }-R \\
(\mathrm{~dB})\end{array}$} & \multirow{2}{*}{$\begin{array}{c}\text { Indice de } \\
\text { redução } \\
\text { sonora } \\
\text { ponderado } \\
\boldsymbol{R}_{w}(\mathrm{~dB}) \\
-\end{array}$} \\
\hline & & & 125 & 250 & 500 & 1.000 & 2.000 & \\
\hline Porta $02 *$ & 44 & 25 & 22,0 & 26 & 29 & 26 & 26 & 27 \\
\hline Porta $03 *$ & 66 & 44 & 24 & 26,0 & 33,0 & 38,0 & 31,0 & 34 \\
\hline Forro de gesso** & 12,5 & 7 & 9 & 15 & 20 & 24 & 39 & 21 \\
\hline
\end{tabular}

Fonte: *Caproni (2012) e **Bistafa (2011).

172 Lima, I. V.; Braga Neto, G. A. N.; Quixaba, G. S.; Melo, G. da S. V. de; Mesquita, A. L. A. 
Figura 18 - Solução 1 e Solução 2 (esquerda para a direita)

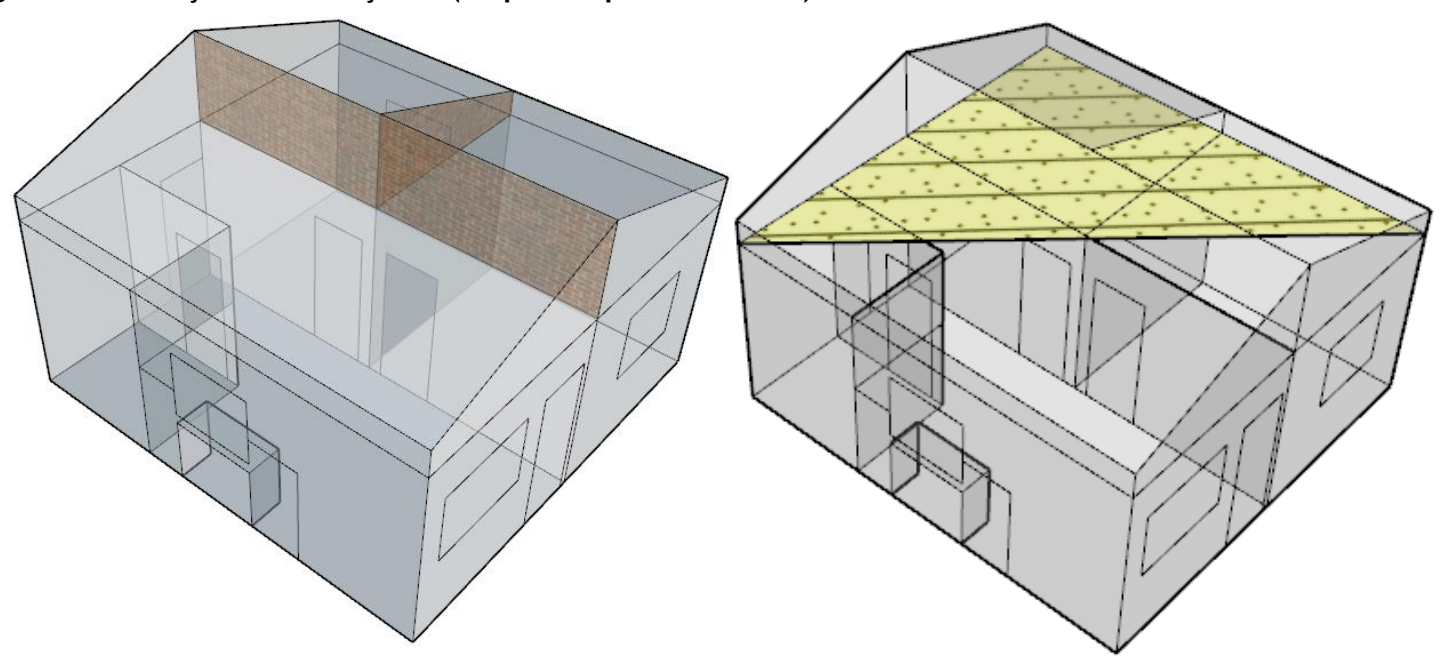

Figura 19 - Solução 3 (esquerda) e Solução 4 (direita)
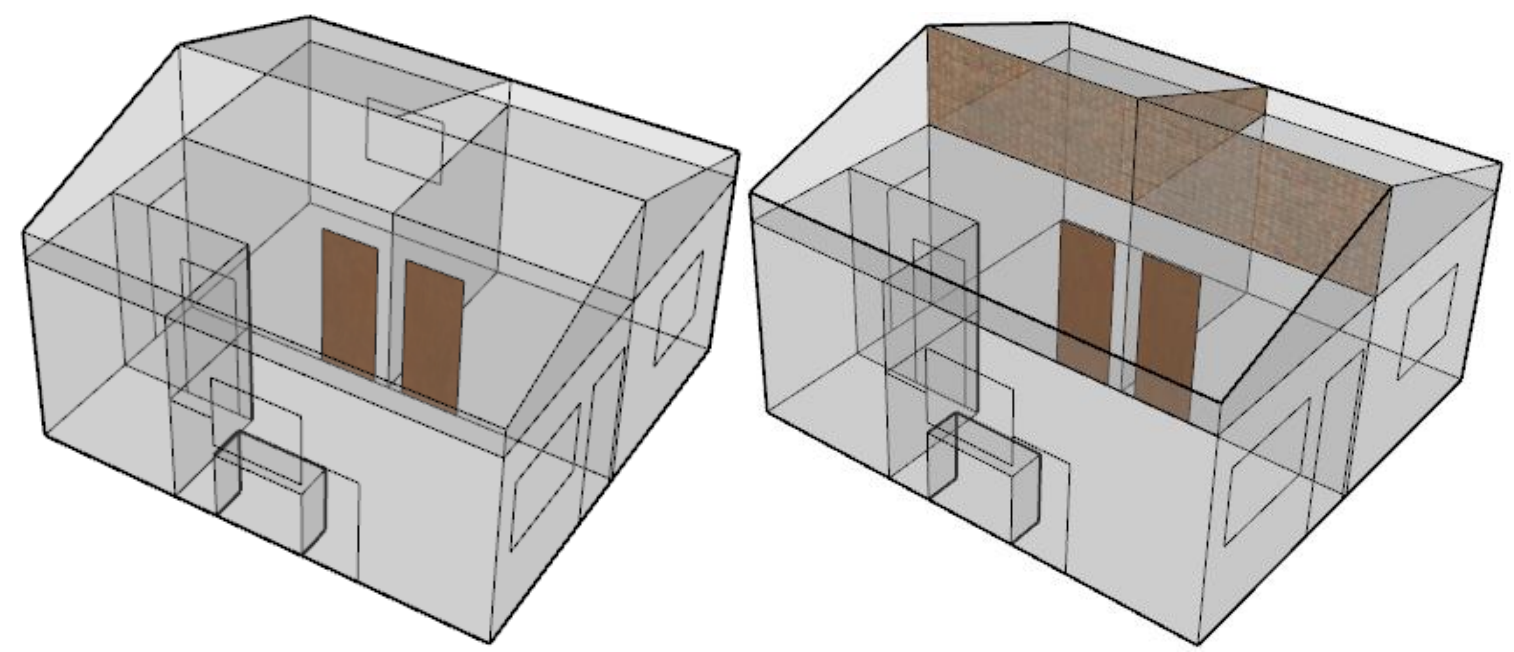

A quarta solução proposta (Solução 4) buscou agir nos dois elementos de pior isolamento, o forro e a porta, pois de acordo com as soluções anteriores, aumentar o isolamento de cada um separadamente não garante o valor de $D_{n T, w}$ mínimo exigido pela norma. Assim, prolongou-se verticalmente as paredes internas de forma a ficarem rentes ao telhado, e foi utilizado ainda o modelo de Porta 2. A Figura 22 apresenta o resultado alcançado de $D_{n T, w}$ igual a $35 \mathrm{~dB}$.

Tendo em vista o acréscimo significativo da Solução 4, a Solução 5 propõe o uso de parede vedando as cavidades do entreforro (ver na Figura 20), acrescentando a área de 10,97 m de parede de alvenaria. Foi considerado um novo tipo de porta descrito por Caproni (2012), sendo uma porta de madeira maciça com espessura de $66 \mathrm{~mm}$ (Porta 3) com $\mathrm{Rw}=34 \mathrm{~dB}$. A Figura 22 mostra que isso garantiu um $D_{n T, w}$ de $40 \mathrm{~dB}$.

A sexta solução proposta para o aumento de $D_{n T, w}$ da vedação vertical entre os ambientes consistiu em aplicar as mesmas intervenções propostas pela Solução 5; no entanto, utilizando o mesmo forro de gesso utilizado na Solução 2, em vez do forro existente. Entretanto, de acordo com a Figura 22, nota-se que não houve aumento no valor de $D_{n T, w}$. Isso ocorreu pelo fato de a elevação da parede de alvenaria, por si só, já ser suficiente para reduzir a propagação sonora no entreforro.

As seis primeiras soluções propostas utilizando o modelo computacional não envolviam uma alteração no leiaute da planta da casa avaliada, apenas melhorias no isolamento dos componentes da vedação entre os recintos. No entanto, como visto no parágrafo anterior, o valor máximo da $D_{n T, w}$ obtido não atende ao critério adotado nessa pesquisa de acordo com a NBR 15575 (ABNT, 2013). Dessa forma, a sétima solução (Solução 7) propõe uma alteração na planta da residência do PMCMV, utilizando uma área de circulação 
fechada com porta entre a cozinha e os quartos (ver Figura 21), contribuindo, assim, para dificultar a transmissão do som via portas. No entanto, essa proposta, além de acrescentar $3,45 \mathrm{~m}^{2}$ de parede de alvenaria, também reduz em $0,45 \mathrm{~m}^{2}$ a área útil de cada quarto. Foram empregadas as mesmas modificações da Solução 5 .

Como resultado, obteve-se aumento expressivo no valor de $D_{n T, w}$ que passou de $23 \mathrm{~dB}$ para $46 \mathrm{~dB}$ após a Solução 7 (ver Figura 22). As intervenções nos materiais e a modificação no leiaute garantiram também que a Solução 7 apresentasse o melhor desempenho entre as soluções propostas, atendendo os critérios mais exigentes da norma NBR 15575 (ABNT, 2013) em relação ao isolamento dos sistemas de vedações verticais (ver Tabela 1), garantindo também, segundo a norma, uma baixa inteligibilidade de fala no recinto adjacente, sendo possível ouvir sem discernir o que se fala (ver Tabela 2)

\section{Figura 20 - Solução 5 (esquerda) e Solução 6 (direita)}
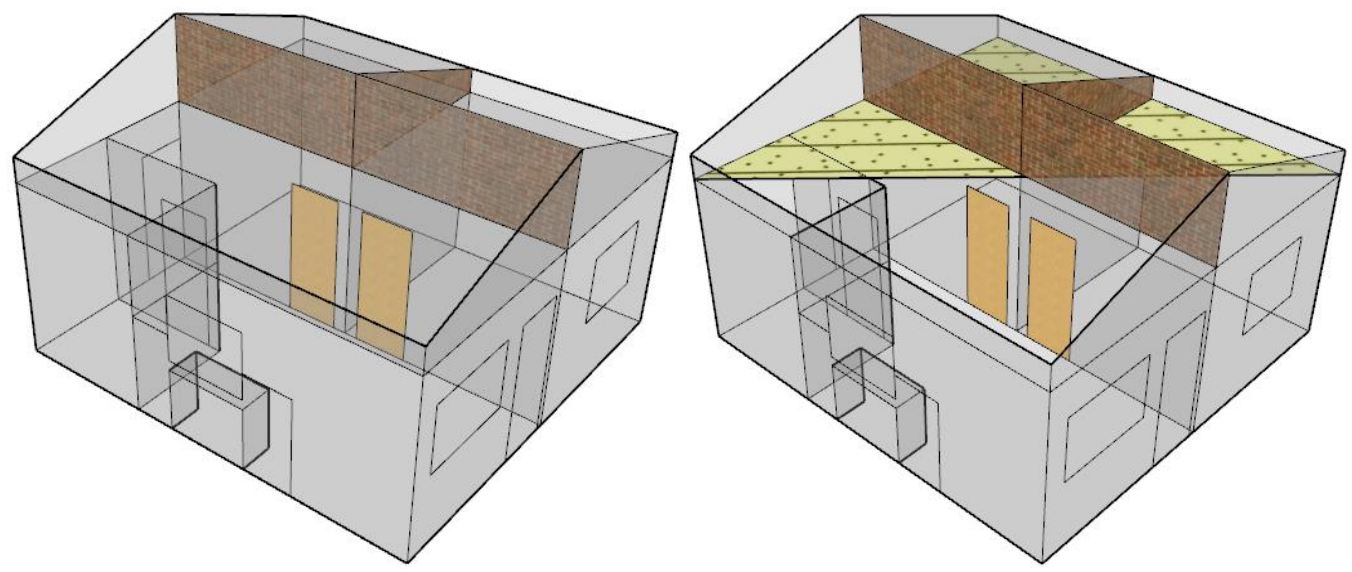

Figura 21 - Solução 7
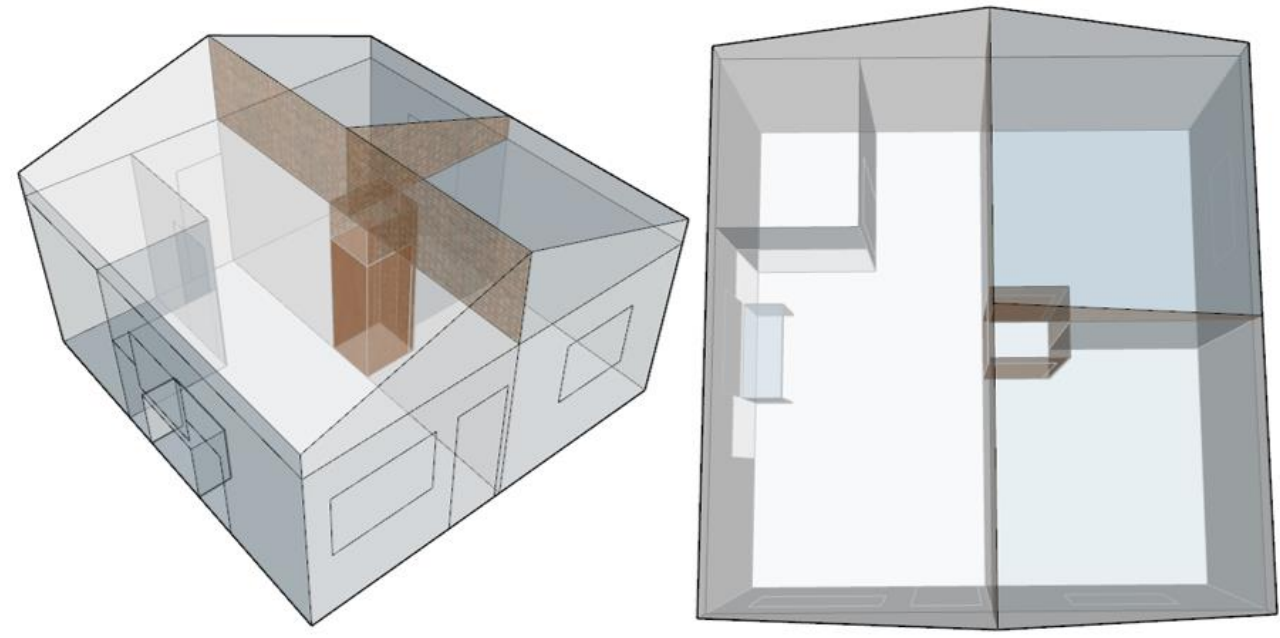

174 Lima, I. V.; Braga Neto, G. A. N.; Quixaba, G. S.; Melo, G. da S. V. de; Mesquita, A. L. A. 
Figura 22 - Valores de DnT e DnT,w obtidos para as soluções propostas

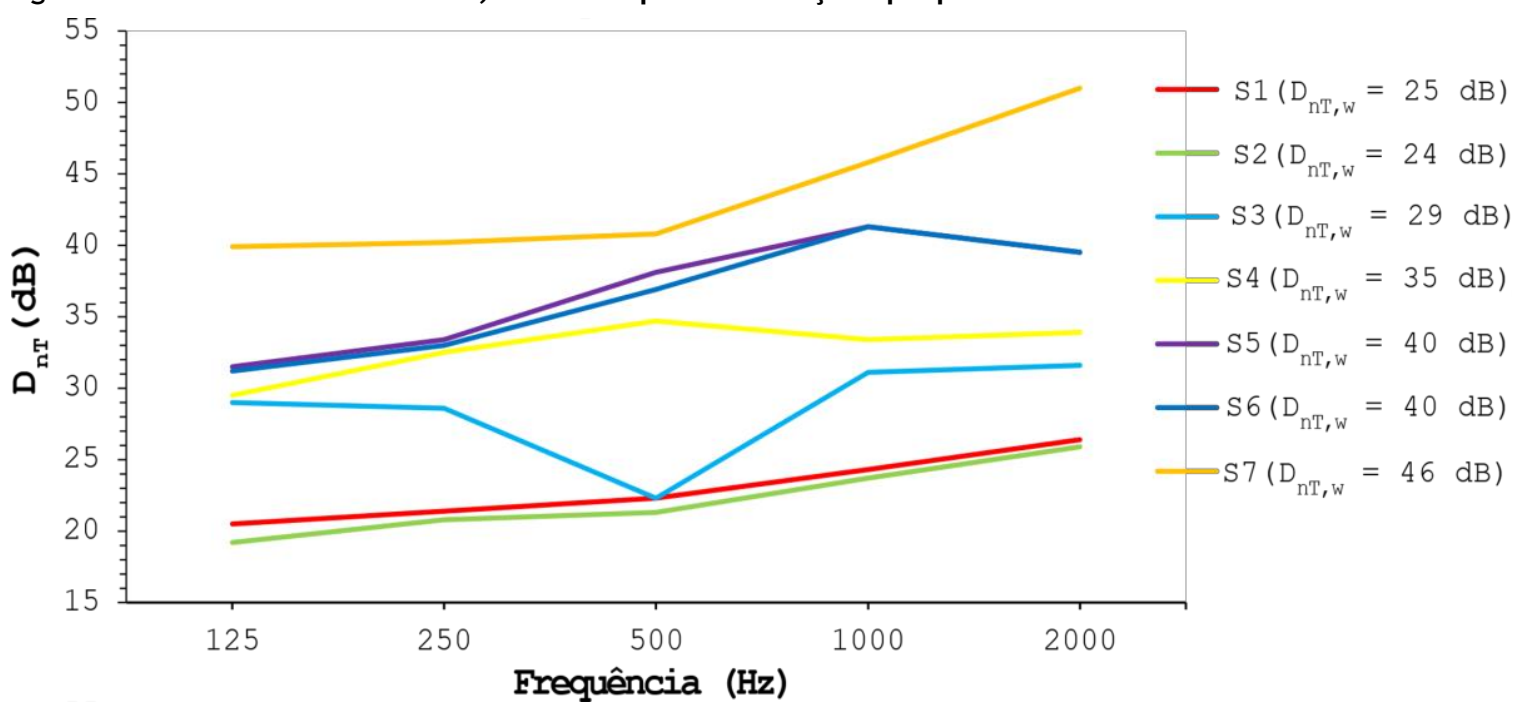

\section{Considerações finais}

Apesar de a norma NBR 15575 (ABNT, 2013) estabelecer os limites de desempenho mínimo, de acordo com a literatura encontram-se muitos casos em que edificações não atendem a esses critérios. Com edificações do PMCMV também não é diferente. Dessa forma, este artigo apresenta uma metodologia de solução eficaz para o problema, por meio de modelagem numérica da edificação. No presente estudo de caso, a modelagem de uma edificação do PMCMV foi realizada por meio do método de traçados de raios, utilizando o software comercial Odeon. Para o estabelecimento das propriedades acústicas dos elementos do modelo, além de informação da literatura e da biblioteca do software, foi necessário também realizar ensaios experimentais em laboratório para determinação das caraterísticas do forro da edificação.

Para a finalização do modelo, é imprescindível a sua calibração com os dados experimentais. Essa calibração foi feita por meio da diferença padronizada de nível ponderada. Apesar de os tempos de reverberação simulados não estarem muito próximos dos valores experimentais para determinadas frequências, isso não fez com que os valores de $D_{n T, w}$ numéricos e experimentais ficassem distantes.

Com o modelo calibrado, foram buscadas várias soluções para elevar o nível de isolação da vedação vertical interna de um dormitório da edificação. Uma das soluções propostas atingiu o valor buscado de $45 \mathrm{~dB}$ para $D_{n T, w}$. Contudo, outras soluções podem ser testadas, tais como paredes drywall.

Como limitações do trabalho, não foram levadas em contas transmissões sonoras pelos flancos, assim como a influência de defeitos na execução das partições isolantes (frestas) que possam reduzir o seu isolamento, o que pode resultar na modelagem um valor de isolamento superior ao valor real. Portanto, devem ser usados os menores valores de $R$ da literatura, que mais se aproximam aos valores de ensaios in situ.

Finalmente, o trabalho mostrou que por meio de simulações numéricas de um modelo validado é possível encontrar soluções virtuais para um problema de não atendimento à norma de desempenho, e assim poder verificar quais intervenções físicas devem ser aplicadas com segurança na edificação para se obter uma solução exitosa.

\section{Referências}

ANSAY, S.; ZANNIN, P. H. T. Using the Parameters of Definition, D50, and Reverberation Time, RT, to Investigate the Acoustic Quality of Classrooms. Canadian Acoustics - Acoustique Canadienne, v. 44, n. 4, p. 6-11, 2016.

ASSOCIACÃO BRASILEIRA DE NORMAS TÉCNICAS. NBR 10152: níveis de pressão sonora em ambientes internos a edificações. Rio de Janeiro, 2020a.

ASSOCIAÇÃO BRASILEIRA DE NORMAS TÉCNICAS. NBR 15575: edificações habitacionais: desempenho. Rio de Janeiro, 2013. 
ASSOCIAÇÃO BRASILEIRA DE NORMAS TÉCNICAS. NBR ISO 10052: acústica: medições em campo de isolamento a ruído aéreo e de impacto e de sons de equipamentos prediais: método simplificado. Rio de Janeiro, 2020b.

ASSOCIAÇÃO BRASILEIRA DE NORMAS TÉCNICAS. NBR ISO 16283-1: acústica: medição de campo do isolamento acústico nas edificações e nos elementos de edificações: parte 1: isolamento a ruído aéreo. Rio de Janeiro, 2018.

ASSOCIACÃO BRASILEIRA DE NORMAS TÉCNICAS. NBR ISO 3382-2: acústica: medição de parâmetros de acústica de salas: parte 2: tempo de reverberação em salas comuns. Rio de Janeiro, 2017.

BISTAFA, S. R. Acústica aplicada ao controle de ruído. 2. ed. São Paulo: Edgar Blucher, 2011.

BRANDÃO, E. Acústica de salas: projeto e modelagem. São Paulo: Blucher, 2016.

BUENO, G. M. et al. Verificação das condições acústicas de habitação de interesse social de acordo com a norma brasileira NBR 15575. Revista AIDIS de Ingeniería y Ciencias Ambientales: Investigacion, desarrolo y práctica, v. 12, n. 3, p. 30-51, 2019.

CAPRONI, C. S. Impacto das frestas em caixilhos sobre a isolação sonora de fachada. São Paulo, 2012. Dissertação (Mestrado em Habitação: Planejamento e Tecnologia) - Instituto de Pesquisas Tecnológicas do Estado de São Paulo, São Paulo, 2012.

CHRISTENSEN, C. L. ODEON ${ }^{\odot}$ Room Acoustics Software, Version 12, User Manual, Kgs. Lyngby: Odeon $^{\odot} \mathrm{A} / \mathrm{S}, 2013$.

COSTA, G. L.; LACERDA, A. B. M.; MARQUES, J. Ruído no contexto hospitalar: impacto na saúde dos profissionais de enfermagem. Revista CEFAC, v. 15, n. 3, p. 642-652, maio/jun. 2013.

FERREIRA, J. A. C.; ZANNIN, P. H. T. Determinação de coeficientes de isolamento acústico: medições in situ e simulação computacional. Ambiente Construído, Porto Alegre, v. 7, n. 2, p. 15-29, abr./jun. 2007.

GUIMARÃES, E.V.C. Influência do ruído de tráfego em edifícios e proposta de solução desenvolvida com auxílio de modelos numéricos. Belém, 2011. Dissertação (Mestrado em Engenharia Mecânica) Universidade Federal do Pará, Belém, 2011.

HALLIWELL, R. E.; QUIRT, J. D. Controlling interoffice sound transmission through a suspended ceiling. Journal of the Acoustical Society of America, v. 90, n. 3, p. 1446-1453, 1991.

INTERNATIONAL ORGANIZATION FOR STANDARDIZATION. ISO 6241: performance standards in buildings: principles for their preparation and factors to be considered. London, 1984.

INTERNATIONAL ORGANIZATION FOR STANDARDIZATION. ISO 717-1: acoustics: rating of sound insulation in buildings and of building elements: part 1: airborne sound insulation. Genève, 2013.

KUHN, E. M. Análise do desempenho acústico de edificação habitacional de âmbito social conforme a NBR 15575. Lajeado, 2015. Trabalho de Conclusão de Curso (Bacharelado em Engenharia Civil) - Centro Universitário UNIVATES, Lajeado, 2015.

LIMA, P. R.; VERGARA, E. F. Simulação acústica de uma sala multiuso para a prática musical: possibilidades de adaptação ao uso. Ambiente Construído, Porto Alegre, v. 18, n. 3, p. 161-173, jul./set. 2018.

LORENZI, L. S.; SILVA FILHO, L. C. P. Análise de desempenho de paredes de concreto armado frente a ABNT NBR 15575. In: CONGRESSO BRASILEIRO DO CONCRETO, 57., Bonito, 2015. Anais [...] Bonito, 2015.

NAVARRO, J. M.; ESCOLANO, J. Simulation of building indoor acoustics using an acoustic diffusion equation model. Journal of Building Performance Simulation, v. 8, n. 1, p. 1-13, 2015.

PIRES, M. R. Análise comparativa da norma de desempenho, ABNT NBR 15575: 2013 com uma tipologia do Programa Minha Casa Minha Vida. Belo Horizonte, 2015. Monografia (Especialização em Construção Civil) - Escola de Engenharia da Universidade Federal de Minas Gerais, Belo Horizonte, 2015.

PROACÚSTICA. Manual ProAcústica sobre a norma de desempenho. São Paulo: Ed. RUSH Gráfica e Editora, 2013.

176 Lima, I. V.; Braga Neto, G. A. N.; Quixaba, G. S.; Melo, G. da S. V. de; Mesquita, A. L. A. 
RANGEL, J. A. et al. Programa Minha Casa Minha Vida e sua repercussão no regional: um estudo sobre o delta do Rio Amazonas. Revista Brasileira de Gestão e Desenvolvimento Regional, v. 16, n. 1, p. 45-57, 2020 .

RINDEL, J. H.; CHRISTENSEN, C. L. Modelling airborne sound transmission between coupled rooms. In: JOINT BALTIC-NORDIC ACOUSTICS MEETING, Reykjavik, 2008. Proceedings [...] Reykjavik, 2008.

SANTOS FILHO, V. M.; SPOSTO, R. M.; CALDAS, L. R. Análise do desempenho acústico de fachadas ventiladas de porcelanato à luz da norma de desempenho: estudo de caso em um edifício habitacional em Brasília-DF. Revista Eletrônica de Engenharia Civil, v. 13, n. 2, p. 116-130, 2017.

SANTOS NETO, N. A. Caracterização do isolamento acústico de uma parede de alvenaria estrutural de blocos cerâmicos. Santa Maria, 2006. Dissertação (Mestrado em Engenharia Civil) - Universidade Federal de Santa Maria, Santa Maria, 2006.

SANTOS, G. B. Análise de condicionamento acústico de sala de aula utilizando painéis de fibras vegetais por meio de simulação computacional. Trabalho de Conclusão de Curso. Faculdade de Engenharia Mecânica. Universidade Federal do Pará, Belém, 2019.

SORGATO, M. J. et al. Análise do procedimento de simulação da NBR 15575 para avaliação do desempenho térmico de edificações residenciais. Ambiente Construído, Porto Alegre, v. 14, n. 4, p. 83101, out./dez. 2014.

TENENBAUM, R. A.; CAMILO, T. S. Método híbrido para simulação numérica de acústica de salas: teoria, implantação computacional e validação experimental. In: SEMINÁRIO MÚSICA CIÊNCIA TECNOLOGIA: ACÚSTICA MUSICAL, 1., São Paulo, 2004. Anais [...] São Paulo, 2004.

TOUTONGE, J. A. Projeto e construção de câmaras reverberantes em escala reduzida para o estudo das características de perda de transmissão de divisórias confeccionadas a partir de materiais regionais. Belém, 2006. Dissertação (Mestrado em Engenharia Mecânica) - Universidade Federal do Pará, Belém, 2006.

VORLÄNDER, M. International round robin on room acoustical computer simulations. In:

INTERNATIONAL CONGRESS ON ACOUSTICS, 15., Trondheim, 1995. Proceedings [...] Trondheim, 1995.

\author{
Isadora Veloso Lima \\ Instituto de Tecnologia | Universidade Federal do Pará | Rua Augusto Corrêa, 01, Guamá | Belém - PA - Brasil | CEP 66075-110 | Tel.: \\ (91) 3201-8967 | E-mail: doiaveloso@msn.com \\ Gerardo Alves Nogueira Braga Neto \\ Instituto de Tecnologia | Universidade Federal do Pará | Tel.: (91) 99140-5851 | E-mail: gerardo-nogueira@hotmail.com \\ Gabriel Soares Quixaba \\ Instituto de Tecnologia | Universidade Federal do Pará | Tel.: (91) 99330-7867 | E-mail: gsquixaba@gmail.com \\ Gustavo da Silva Vieira de Melo \\ Instituto de Tecnologia | Universidade Federal do Pará | Tel.: (91) 3201-7961 | E-mail: gmelo@ufpa.br
}

Alexandre Luiz Amarante Mesquita

Instituto de Tecnologia | Universidade Federal do Pará | Tel.: (91) 3201-7251 | E-mail: alexmesq@ufpa.br

\author{
Ambiente Construído \\ Revista da Associação Nacional de Tecnologia do Ambiente Construído \\ Av. Osvaldo Aranha, $99-3^{\circ}$ andar, Centro \\ Porto Alegre - RS - Brasil \\ CEP 90035-190 \\ Telefone: +55 (51) 3308-4084 \\ www.seer.ufrgs.br/ambienteconstruido \\ www.scielo.br/ac \\ E-mail: ambienteconstruido@ufrgs.br
}

